\title{
Biological Activities of Secretory RNases: Focus on Their Oligomerization to Design Antitumor Drugs
}

\author{
Giovanni Gotte* and Marta Menegazzi \\ Biological Chemistry Section, Department of Neuroscience, Biomedicine and Movement Sciences, University of Verona, \\ Verona, Italy
}

OPEN ACCESS

Edited by:

Ester Boix,

Autonomous University of Barcelona, Spain

Reviewed by:

Olga N. llinskaya,

Kazan Federal University, Russia

François J. M. A. Meurens, UMR INRA-Oniris 1300 Oniris-Nantes Atlantic National College of Veterinary Medicine, France

Elio Pizzo,

University of Naples Federico II, Italy

*Correspondence:

Giovanni Gotte

giovanni.gotte@univr.it

Specialty section:

This article was submitted to

Viral Immunology,

a section of the journal

Frontiers in Immunology

Received: 01 August 2019

Accepted: 22 October 2019

Published: 26 November 2019

Citation:

Gotte G and Menegazzi M (2019) Biological Activities of Secretory

RNases: Focus on Their

Oligomerization to Design Antitumor Drugs. Front. Immunol. 10:2626.

doi: 10.3389/fimmu.2019.02626
Ribonucleases (RNases) are a large number of enzymes gathered into different bacterial or eukaryotic superfamilies. Bovine pancreatic RNase A, bovine seminal BS-RNase, human pancreatic RNase 1, angiogenin (RNase 5), and amphibian onconase belong to the pancreatic type superfamily, while binase and barnase are in the bacterial RNase N1/T1 family. In physiological conditions, most RNases secreted in the extracellular space counteract the undesired effects of extracellular RNAs and become protective against infections. Instead, if they enter the cell, RNases can digest intracellular RNAs, becoming cytotoxic and having advantageous effects against malignant cells. Their biological activities have been investigated either in vitro, toward a number of different cancer cell lines, or in some cases in vivo to test their potential therapeutic use. However, immunogenicity or other undesired effects have sometimes been associated with their action. Nevertheless, the use of RNases in therapy remains an appealing strategy against some still incurable tumors, such as mesothelioma, melanoma, or pancreatic cancer. The RNase inhibitor (RI) present inside almost all cells is the most efficacious sentry to counteract the ribonucleolytic action against intracellular RNAs because it forms a tight, irreversible and enzymatically inactive complex with many monomeric RNases. Therefore, dimerization or multimerization could represent a useful strategy for RNases to exert a remarkable cytotoxic activity by evading the interaction with RI by steric hindrance. Indeed, the majority of the mentioned RNases can hetero-dimerize with antibody derivatives, or even homo-dimerize or multimerize, spontaneously or artificially. This can occur through weak interactions or upon introducing covalent bonds. Immuno-RNases, in particular, are fusion proteins representing promising drugs by combining high target specificity with easy delivery in tumors. The results concerning the biological features of many RNases reported in the literature are described and discussed in this review. Furthermore, the activities displayed by some RNases forming oligomeric complexes, the mechanisms driving toward these supramolecular structures, and the biological rebounds connected are analyzed. These aspects are offered with the perspective to suggest possible efficacious therapeutic applications for RNases oligomeric derivatives that could contemporarily lack, or strongly reduce, immunogenicity and other undesired side-effects.

Keywords: ribonucleases, RNase oligomers, domain swapping, cytotoxicity, antitumor activity 


\section{INTRODUCTION}

\section{RNases}

Ribonucleases (RNases) form a very large group of bacterial or eukaryotic enzymes that have been deeply studied in the last 50-60 years (1). RNases catalyze the hydrolysis of a variety of different RNA substrates (2), so that a logical and suitable classification in families may not be easy or immediate. Furthermore, a cell contains a large number of distinct RNases, approaching as many as twenty members, often characterized by different or sometimes overlapping substrate specificities (3). However, notwithstanding this complexity, a useful classification may descend from differentiating intracellular RNases from the ones secreted in extracellular fluids that are also called secretory RNases $(1,4,5)$, on which we will focus our attention.

\section{Pancreatic-Type RNases}

The group of secretory RNases has included, since the 60s, an increasing number of members that have been discovered, characterized and classified as the "pancreatic-type" RNases (5, 6). This definition originates from the bovine pancreatic RNase $\mathrm{A}$, a $13.7 \mathrm{kDa}$ and $124 \mathrm{AA}$ residues enzyme that has been the most studied RNase in the past $(7-10)$. The already 20 years old review of Raines still remains an exhaustive milestone that describes many aspects of RNase A, especially its catalytic activity (11). More recently, RNases of the pancreatic-type superfamily proto-type do not refer sometimes to the bovine variant but to human pancreatic RNase (12), called HP-RNase or RNase 1 (6). This variant is not expressed only in the pancreas, but in almost all tissues (13), and displays a highly similar identity sequence as RNase A, although the former is more basic than the latter (14). Both RNase A and RNase 1 can be variably glycosylated at the expense of some Asn residues, especially Asn34, with RNase 1 being more prone to suffer this modification than the former $(15,16)$. Besides these two members, other important RNases have been included in the mentioned superfamily although they are not secreted by the pancreas: deserving notice are the cytotoxic bovine seminal RNase (BS-RNase) (17), the unique natively dimeric member of the superfamily $(18,19)$, and also RNase 5 or angiogenin (ANG) (20). ANG is 123 AA residues long and is so called because of its active role in the new vessels formation, but it exerts ribonucleolytic activity against tRNAs as well (21-23). Again, other RNases belonging to non-mammalian species, such as birds or amphibians, are also known $(24,25)$. Among these RNases, the most studied are the 114 AA residues amphinase and, above all, the smallest variant called ranpirnase or P-30 protein, which is formed only by 104 AA residues $(26,27)$. This latter variant is commonly called onconase (ONC) because of its remarkable antitumor activity exerted against many cancer types $(27,28)$. Although not being mammalian, both amphinase and $\mathrm{ONC}$ have been included in the pancreatic-type superfamily because of their structural homology with pancreatic RNases, being characterized only by about $30 \%$ sequence identity (28). Hence, the main general requisites necessary to belong to the pancreatic-type superfamily are (i) the conservation of a catalytic triad formed by one Lys and two His residues, as H12/K41/H119 is for RNase A, (ii) an elevated homology folding resembling the
V-like, or kidney-like shape of RNase A and (iii) the distribution of the basic charged residues that should be almost totally located in the proximity of the active site region (5) to allow an efficacious accommodation of the negatively charged RNA polymer in the RNase active site cavity (29). Therefore, many of the mentioned basic residues are considered "subsites" crucial for an optimal catalysis $(11,30)$ or they are sometimes considered even as secondary active sites, as was recently reported for human RNase 6 (31). This aspect acquires increasing importance if we recall that RNases can often interact with a polymeric substrate and not only with short oligonucleotides (29). We also point out Arnold's quite interesting review in which the principal features of mammalian and amphibian RNases have been exhaustively compared (25).

\section{Mammalian and Amphibian Secretory RNases and Their Biological Activities}

Up to eight secretory RNase variants, numbered from 1 to 8 , have been characterized today in humans. The already mentioned pancreatic RNase 1 is expressed in all tissues, but it is particularly abundant in endothelial cells (32). Its biological activity features are devoted to controlling the extracellular RNA (exRNA) content in the biological fluids, as will be reported below.

RNases 2 and 3 are instead highly basic eosinophil secretory variants that reciprocally share $67 \%$ identity but only 32 and $26 \%$ with RNase 1, respectively. They are both out of the "pancreatic-type" superfamily because their basic residues are randomly located (5). However, the $134 \mathrm{AA}$ residues long RNase 2 displays an activity against yeast RNA comparable with the one of the pancreatic enzyme (33). RNase 2 is the eosinophil-derived neurotoxin $(\mathrm{EDN})$ that is additionally present in many organs and fluids $(34,35)$. EDN/RNase 2 elicits Purkinje cells death when released into the cerebellum, but it exerts crucial physiological actions taking part in the innate host defense (36). It is released from eosinophilic granules in response to inflammatory mediators, supporting an immune-modulatory role (37). In particular, cytokines, such as CCL11 and CCL24 can induce RNase 2 and also RNase 3 secretion via the PI3K/MAPK pathway $(38,39)$. In addition, RNase 2 displays chemoattractant effects by eliciting both dendritic cells' maturation and activation and also exerts activity against both Respiratory Syncytial and Human Immunodeficiency Viruses $(36,39)$. Indeed, virus infection can trigger eosinophilic RNases release through the toll-like receptors signaling pathways (39). Differently from EDN, the $133 \mathrm{AA}$ residues RNase 3 is eosinophil-specific and is also named the eosinophil cationic protein (ECP) $(40,41)$. ECP is peculiar in the RNase world: in fact, although it is less neurotoxic than EDN, it exerts remarkable bactericidal effects, promoting the agglutination of bacteria cells and cytotoxicity (42) also when its catalytic activity is nil (43). Several inflammatory stimuli trigger ECP release, so that its serum concentration is used as a biomarker of various Th2-phenotype-associated inflammatory diseases, including asthma, allergic rhinitis, dermatitis and bowel disease $(44,45)$. Furthermore, and differently from the other wt-RNases, ECP can form amyloid-like fibrils at acidic $\mathrm{pH}$ (46).

RNase 4 (119 AA residues) is today the least studied human RNase variant, although its ubiquitous expression suggests for 
it an important physiological role (36). It is highly selective for uridine RNA sites of cleavage $(47,48)$, and, similarly to RNase 5 , RNase 4 displays angiogenic activity $(47,49)$. Consequently, it is protective against neuron degeneration by promoting angiogenesis, neurogenesis and neuronal survival under stress (50). Importantly, polymorphisms, and recently, pathogenic mutations have associated RNase 4 with Amyotrophic Lateral Sclerosis (ALS) development $(51,52)$.

The already mentioned 123 AA RNase 5, or ANG, is considered the oldest pancreatic type RNase member (53). It displays three instead of four paired cysteines with respect to the other RNases $(24,53)$, and its ribonucleolytic activity, although being very low, is mandatory for its angiogenetic action $(36,54)$. Its localization is also very important for its somehow contradictory biological functions exerted in different cell compartments and conditions. In fact, in the extracellular space, ANG can trigger growth signaling pathways, such as ERK1/2 and AKT activation, upon its binding to a receptor; however, it is not well-characterized yet $(54,55)$. Inside the cells, instead, its high affinity binding with the cellular ribonuclease inhibitor (RI) switches off its catalytic and biological activities (55). However, not all ANG molecules are sequestered by RI: indeed, the phosphorylated ones can escape RI and enter the nucleus, accumulating in the nucleolus where ANG stimulates ribosomal transcription and exerts its angiogenetic activity (56). In cancer cells, the increase of rRNA production and angiogenesis definitely enhances cell growth and tumor progression (56). Therefore, ANG inhibition can on one hand counteract tumor growth, but, at the same time, could also promote neuronal damage. In fact, as for RNase 4, many loss of function ANG mutants are associated with ALS and/or Parkinson's disease (5759). In the contrast of its nuclear activity, ANG can address itself in the stress granules where it splits tRNA into fragments (tRFs) (60). In this case, ANG can perform different functions through an RNA interference-like mechanism (61). Indeed, ANG is known to trigger the formation of cytotoxic tRFs species upon knockdown of RI (62). Consequently, an induced cell death effect can prevail over ANG angiogenetic action. In conclusion, under different conditions ANG can induce either cell death or survival $(61,63)$.

The 127 AA residues long RNase 6 (64), characterized by two catalytic centers (31), is ubiquitously distributed, including neutrophils and monocytes. RNase 6 is thought to exert an active role in inflammation because its level increases in the urinary tract after infection (65). The antimicrobial properties of this variant are carried out by inducing bacteria agglutination (66). Furthermore, RNase 6, as well as RNase 3, is highly effective against Mycobacterium aurum by inducing an autophagy process in the infected macrophages (67).

Finally, RNase 7 and 8 are formed by 128 and 127 AA residues, respectively, displaying high structural similarity, although the former is expressed in the skin but also in other epithelial tissues and organs and can be induced by growth factors, cytokines and bacterial products (68). Conversely, RNase 8 is principally expressed in the placenta but also in the spleen, lung and testis (69), implying the presence of a defense system against pathogens that cross the placenta to target the fetus (70).
Importantly, we underline that the most important features of the eight human variants are well-described in the two reviews provided by Sorrentino and, more recently, by the group lead by Boix $(39,71)$.

From what has been reported, the peculiar and remarkable biological activities exerted by many RNases would not seem at first to be directly related to their ability to hydrolyze RNA. Instead, for the already mentioned BS-RNase, ANG, ONC, and amphinase, at least a minimal ribonucleolytic activity is mandatory to express their biological actions (72), among which the cytotoxicity against malignant cells emerges $(49,73,74)$, while since the 70s, BS-RNase has been discovered to be also immunosuppressive, embryotoxic, and aspermatogenic $(73,75-$ 77). Interestingly, the history of the findings related to the antitumor action of many RNases has been well-described by Matousek in 2001 (78).

\section{Bacterial RNases}

Considering their structural and functional properties, we report about four bacterial RNases belonging to the RNase N1/T1 microbial superfamily (79). They are as follows: barnase from Bacillus amyloliquefaciens (80-82), binase from B. pimulus (82, 83 ), balifase from $B$. licheniformis (84), and balnase from $B$. altitudinis (85). Barnase is found to be bound with its inhibitor Barstar $(80,81,86)$, but when it dimerizes and contemporarily forms a dibarnase immuno-derivative it exerts a remarkable antitumor activity against many cancer cell types (87-89). Binase is natively dimeric $(83,90)$, and possesses remarkable cytotoxic and antiviral activities against transformed myeloid cells and fibroblasts, also against $\mathrm{SiHa}$ cervix human papilloma virusinfected carcinoma cells, without inducing immune response (83, 91-93). In addition, a molecular mechanism that is carried out without catalytic degradation of RNAs has been suggested by Ilinskaya et al. to explain some binase antitumor effects. Indeed, binase is reported to interact with KRAS, stabilizing the inactive GDP-bound conformation of RAS, thereby inhibiting MAPK/ERK signaling (94). Balifase is then the most stable variant of this group and is not natively dimeric, but it combines parts of binase and barnase features (84). Balnase is almost identical to binase except for its A106T mutated residue (85). However, its biological activities, as well as the ones of balifase, have not been investigated enough yet.

RNases belonging to the T2 family, whose human variant is named RNASET2, also deserve to be mentioned for their remarkable biological activities: they are found in bacteria, plants and viruses but also in animals, and they exert their enzymatic activity at $\mathrm{pH}$ values around 4-5indeed lower than neutral $\mathrm{pH}$, around which the majority of RNases are active (95). RNASET2 is secreted by damaged tissues, exhibits chemotactic activity and initiates immune response(s): in fact, recombinant RNASET2 injection induces fibroplasias, connective tissue remodeling and the recruitment of infiltrating cells expressing macrophage markers (96). Furthermore, humans lacking or carrying RNASET2 mutations suffer neurological disorders or even misfunction in the immune system (97). 


\section{Secretory RNases as Natural Scavengers of Extracellular RNA (exRNA)}

The ca. 20 active RNases present in almost all mammalian cell types process RNA into mature forms to regulate RNA turnover and metabolism and properly tune the associated cellular processes $(98,99)$. Additionally, RNases can also work as alarming sentinels to block several cellular dysfunctions: indeed, they can act as immune regulators or agents inducing tissue repair and remodeling, epithelial barrier protection, body fluid sterility and exRNA clearance (39). Regarding this latter aspect, exRNA promotes the activation of proteases that trigger the blood coagulation factors XI and XII, while a RNase A pretreatment can delay occlusive thrombi formation (100). Moreover, exRNA mediates the endothelial brain permeability and RNase A treatment reduces vessel occlusion, preventing brain edema (101). Furthermore, the in vivo administration of RNase 1 reduced pathological parameters that are characteristic for ischemia/reperfusion injury, thus improving functional myocardial recovery (102). Finally, considering that exRNA is able to increase inflammation by stimulating leukocyte adhesion, transmigration and mobilization of pro-inflammatory cytokines (103), secretory RNases can become crucial modulators of physiological cell functions by acting as natural exRNA scavengers.

Moreover, it has been recently discovered that exRNAs, especially non-coding ones secreted from tumor cells, can act as signals that modify the cell microenvironment and favor tumor progression and metastasis formation (104). The largest part of exRNA released in body fluids is encapsulated inside extracellular vesicles and exosomes or is associated with high density lipoproteins $(105,106)$. Thus, even if in these vesicles exRNA is more protected, most secretory RNases are able to cross the membrane, as it is reported hereinafter, thus exerting an anti-tumor activity to counteract metastatic processes also at the extracellular level (107).

In general, human secretory RNases also display antiinflammatory, antibacterial and antiviral actions, or induce immune response when a large amount of ds-RNA is generated by pathogens $(53,108)$. Additionally, RNase 1 is active against DNA:RNA hybrids, and ds-RNA rather than ss-RNA (12, 109, 110 ), and, to this end, the conservation of its Gly38 residue is crucial to maintaining the full catalytic activity against duplex RNAs (111). Overall, many steps forward have been performed in the comprehension of the antimicrobial effects ascribable to many RNases, and promising results suggest their potential use despite the classic antibiotics that lose efficacy upon the development of resistance $(31,44,112)$.

In summary, almost all the biological activities displayed by the mentioned RNases are strictly dependent on their ribonucleolytic activity vs. ss- and ds-RNA, necessary to regulating the extracellular RNA level $(36,39,100,113)$.

The secreted RNases endowed with relevant biological activities do not display their action only extracellularly, but they are often able to enter the cell to exert their peculiar activities against intracellular RNAs. However, at this step, many difficulties indeed emerge, such as the necessity to have a favorable interaction with cell membranes, a subsequent release in the cytosol and the possibility to evade RI (114). These issues are more extensively described in the next chapters, together with the ability of RNases to form supramolecular structures. The formation of oligomeric moieties can become in fact advantageous for many RNases in terms of acquiring new activities or potentiating pre-existing ones, as well as minimizing undesired interactions, or also reducing adverse side effects in vivo (115-117).

\section{CRUCIAL STEPS FOR CYTOTOXIC EXTRACELLULAR RNASES TO EXERT THEIR ACTIVITY}

\section{Interaction With (Malignant) Cell Membrane and Cell Entering Upon Endocytosis}

The main obstacle for extracellular RNases to exert their antitumor action is represented by the possible difficulty to be cellularly internalized. This occurs through endocytosis (118) and only if a fruitful interaction with the cell membrane occurs. However, the possibility for ONC to be internalized with the mediation of a receptor has been proposed and debated as well (119, 120). Sundlass et al. compared the ability of RNase 1, RNase A and ONC to interact with lipid bilayers, revealing that either electrostatic forces or specific interactions determining the time spent by an RNase near the cell surface are critical for its internalization (121). In addition, Notomista et al. demonstrated that cytotoxic native or engineered dimeric RNases strongly affect membrane aggregation, fluidity and fusion (122). Considering that the most desired biological activity of RNases is to be selectively cytotoxic against malignant cells and that these cells possess a more negatively charged membrane than normal ones, the basicity of each RNase is likely the most important feature necessary to win this challenge. However, the basic net charge per se is not enough for a RNase to be internalized in the cell. In fact, the specific orientation of a RNase molecule can become crucial for a successful approach to the cell membrane: therefore, the selection of the most favorable RNase-membrane interaction patch has been the object of many studies focused especially on ONC and BS-RNase, but also on RNase 1 and RNase A $(12,121-$ 123). In particular, the natively dimeric BS-RNase assumes the most advantageous orientation for its internalization when it faces both N-termini toward the cell membrane (122), and the structure of BS-RNase shows that both N-termini actually adopt the same orientation (19). Furthermore, the G38K-BS-RNase mutant, being endowed with an additional cationic key-residue oriented in the same direction of the N-terminus, interacts with the membrane more strongly and is even more cytotoxic than the wild type $(124,125)$. Hence, the the orientation of the basic charges could also affect the cytotoxic potential of other RNases and of their oligomers. Other studies showed instead that BSRNase approaches the membrane differently from ONC (121) but similarly to RNase A and RNase 1 (121, 122). RNase 1 in turn showed itself to be the monomeric variant accompanied with the highest propensity to be internalized in cells (12). Moreover, RNase cellular internalization can be considered also 
residue-specific: in fact, wt-ONC is less efficiently internalized than its so called "R-mutant," in which all lysine residues but the two crucial for catalysis are replaced by arginine (126). It has to be underlined, however, that if the RNase basic net charge is randomly increased, the advantage represented by a favored internalization may be counteracted once in the cells by the RNase affinity increase toward the negatively charged RI (127).

Finally, and interestingly, we note that BS-RNase has a high binding affinity also toward the extracellular matrix (ECM), since its cytotoxicity against $\mathrm{CHO}$ cells grown in suspension is quite lower than the one exerted vs. the same adherent cell subtype (128).

\section{Intracellular Routing of RNases}

Once they have entered the cell, RNases must overpass other obstacles to exert their activity. Some of these issues have been well-presented in another review contributed by Arnold (129). The cytotoxic potency of different RNases is certainly due to optimal cell membrane interaction and endocytic internalization, but also to their resistance against proteolytic degradation in the endosomes/lysosomes/trans Golgi and their fruitful release into the cytosol (118).

Some discordant data are present in literature regarding the actual internalization mechanism of RNases: in fact, while Haigis and Raines demonstrated that ONC, RNase A and its G88R variant are internalized in early endosomes of HeLa and K562 cells by a clathrin- and caveolae-independent mechanism (120), Rodriguez et al. indicated that Jurkat cells endocytose ONC through a dynamin-dependent route, presumably following a clathrin/AP-2-mediated endocytic pathway (130). However, these controversial data suggest that RNases go through diverse routes to cross the membrane of different cell lines. In the RNases routing toward their final cytosolic destination, the first step is their delivery to early endosomes, while instead the features of the subsequent intracellular routing steps have not been completely understood so far. BS-RNase is internalized in endosomal vesicles either in normal or malignant cells; but only in the latter ones, where it is cytotoxic, does it reach the Golgi apparatus, i.e., the intracellular station, before its cytosolic delivery $(131,132)$. In addition, a BS-RNase variant characterized by a C-terminus engineered with a key-sequence that is useful for its localization in the endoplasmic reticulum is not cytotoxic because it is unable to be released in the cytosol to elicit its anti-tumor activity (131). Furthermore, when two RNase 1 mutants designed to evade RI were fused with a scFv fragment for human CD7 antigen to be delivered into leukemic cells, they were able to bind to $\mathrm{T}$ cell surface and to be internalized, but they were not cytotoxic. This is because they were delivered in the lysosomal compartment and there degraded. Instead, cytotoxicity was restored when they were internalized by transfection (133). In contrast, the human immuno-ErbB2-RNase 1 fusion protein was internalized in SKBR3 cells, and its direct transfer from endosomes to the cytosol was demonstrated. In this case, cell death occurred through apoptosis with an $\mathrm{IC}_{50 \%}$ of $12 \mathrm{nM}$ (134). More recently, an interesting strategy to intracellularly internalize RNases was proposed: three cationic amine-reactive linkers were attached to RNase A, and the stability of these conjugates was $\mathrm{pH}$-dependent.
Therefore, the endocytic vesicles' acidic environment led to the release of high cytosolic amounts of RNase A to make its concentration high enough to overcome the RI binding capacity and become cytotoxic (135).

However, RNases can have distinct but not always successful outcomes in several cellular organelles, such as endosomes, lysosomes, ER and the trans-Golgi network (136). Thus, many studies have been performed to unveil the intracellular routing of extracellular RNases once internalized by endocytosis, and the relative results indicated that diverse RNases, such as ONC or BS-RNase as well as RNase A, RNase 1, or ANG follow different cellular pathways within one another, as described or proposed in several reports $(32,118,120,128,130-132,135)$.

Finally, it has to be remembered that the capability to exert their activity in the nucleus is crucial for some RNases: indeed, ANG/RNase 5 needs to be enzymatically active (72) but also to enter the nucleus to exert its fundamental angiogenic activity in both normal and cancer cells $(56,137)$. To do so, ANG exploits its surface loop involving the R31-R32-R33 Arg-triplet, whose replacement provokes the block of either its nuclear import or angiogenesis (138). Notably, insertion(s) of nuclear localization sequence(s) (NLS) involving Arg residues located in loop(s) present in RNase A or RNase 1 variants make them able to enter the nucleus and exert angiogenetic (139) or cytotoxic activities (140, 141), respectively. This evidence suggests that different RNases located in the same compartment can address their action against different RNA targets to trigger diverse biological reactions. Then, considering the human nature of RNase 1, its nuclear activity becomes advantageous in terms of obtaining cytotoxic variants devoid of any immunogenicity.

\section{Evasion From the Cytosolic RNase Inhibitor}

As already mentioned, a huge obstacle for an RNase to be actually active in the cell is represented by the interaction with RI. This $50 \mathrm{kDa}$ protein was firstly extracted from the rat liver while the human variant was isolated from placenta (142), and its interaction with RNases was firstly detected with ANG (143). $\mathrm{RI}$ is a negatively charged horseshoe-shaped and leucine-rich macromolecule that is ubiquitously expressed in almost all cells (114). RI was considered for many years to be present only in the cell cytosol, but more recently its presence has been detected also in mitochondria and nuclei (144). All RI biological functions have not been completely clarified, but, considering its numerous cysteine residues, its contribution to the redox cellular homeostasis has been stated (145). RI can form very tight complexes with RNase A (146) and with RNase 1 (147), ANG (148) and EDN (149). RI interacts also with RNase 7 (150) and is highly conserved in the cells of many mammalian species, but is present also in non-mammalian ones (151). Most of the RNase-RI complexes characterized so far are not dissociable because their $\mathrm{K}_{\mathrm{d}}$ values fall into the pico- to femtomolar range (152). The RNase-RI complex structure(s) explain(s) why RNase activity is inhibited, being the enzyme moiety caged inside the RI cavity (153). 
ANG can sterically evade the cytosolic interaction with RI when it undergoes phosphorylation at some Ser/Thr residues that are crucial for RI binding (55). In this way, it can be internalized in the nucleus to exert its angiogenetic activity. Instead, ONC exceptionally evades or extensively lowers its affinity for RI because it is devoid of the K7 and G88 key-residues allowing, in RNase A, the interactions necessary to form the tight RNase-RI complex. For this reason, ONC can actually display its remarkable cytotoxicity (154). Hence, site-specific mutagenesis approaches made also RNases of mammalian origin capable of evading RI and exerting their cytotoxic potential (155-157). This could be considered not completely true if we remember that many years ago, Ledoux found that wt-RNase A can be active against tumors either in vitro or in vivo (158-160). However, we must underline that high RNase A doses, not $<200 \mathrm{mg} /$ mouse (159), or concentrations not lower than $2 \mathrm{mg} / \mathrm{mL}(\sim 145 \mu \mathrm{M})$ in the cell culture medium (160), were used in those cases. Therefore, even if all RNase A molecules did not enter the cells, these doses certainly overpassed the cytosolic RI concentration, that is about $4 \mu \mathrm{M}$ (161). Hence, the exceeding RNase A amount should be free to exploit RI saturation and exert cytotoxic activity, in line with that reported by Liu et al. (135). We recall that, beyond ONC, mammalian BS-RNase is also cytotoxic: indeed, being natively dimeric, it can sterically evade RI (162). It is well-known, in fact, that the monomeric BS-RNase derivative, although retaining its ribonucleolytic activity, definitely loses its cytotoxicity because it is sequestered by RI $(163,164)$. Finally, another way to make potentially active RNases actually cytotoxic could be to silence the RI action (165), even though the sensitivity to RI is not the unique factor determining cell cytotoxicity. To this point, conflicting results support opposite arguments: certainly, it has been demonstrated that non-cytotoxic RNases are unable to affect HeLa cells viability also after being deprived of RI (166). On the contrary, non-covalent artificial dimers of RNase A, although being RI-sensitive (167), were found to be cytotoxic against some malignant leukemia cell lines at a concentration of about $20 \mu \mathrm{g} / \mathrm{mL}$ (168), even if they were definitely inactive against pancreatic cancer cells (125).

From what has been reported, we can envisage that if an RNase is induced to oligomerize, and, thus, to be bulkier than its native monomer, this would augment the charge density of the enzyme moiety to help its internalization in tumor cells. Furthermore, the increased steric hindrance would help to evade the RI interaction, as BS-RNase does. This strategy, and what it is correlated with, will be presented and discussed in the next chapters.

\section{RNASE OLIGOMERIZATION: A STRATEGY TO OBTAIN STABLE AND MORE ACTIVE RNASE DERIVATIVES}

Each step necessary to exert their biological action could represent a huge obstacle for RNases. Hence, point mutations as well as post-transduction or also in vitro modifications might be helpful to overcome these barriers. Moreover, in this context, a controlled induction of protein self-association leading to natural or artificial RNase oligomers may represent a fruitful strategy to be promoted or, conversely, underwent by the organism to obtain RNase derivatives that exert remarkable biological activities. In line with this argument, RNase or, generally, protein oligomerization, can occur spontaneously or can be induced also by the cell environment or by an in vivo context $(117,169,170)$. Again, oligomerization can be provoked artificially in vitro to obtain a controlled plethora of products that can be characterized in light of the desired goal.

\section{Covalent Oligomerization of RNases}

Artificial oligomerization can be induced to form covalently linked derivatives upon the reaction of a protein with bifunctional or multifunctional cross-linkers. In this way, stable hetero- or homo-oligomers can be produced, but with the concomitant modification of one or more AA residue(s). Dimerization or oligomerization can be obtained also with conditions favoring a spontaneous protein self-association. Again, the cross-linking of the subunits of a protein can occur spontaneously or in response to a cell signal, in membrane proteins or cell factors upon undergoing photochemical events, phosphorylation, apo/holo transitions, or even other posttransduction modifications. To date, within mammalian RNases, only BS-RNase is known to be a native homo-dimer thanks to the formation of two antiparallel disulfides involving the Cys31 residue of one subunit with the Cys32 of the other, and viceversa (18). These two residues are instead different from cysteine in all other known RNases. Therefore, many strategies have been followed to induce a RNase to dimerize or oligomerize by forcing it to react with the appropriate cross-linking reagent(s). It should be taken into account, however, that any chemical modification can somehow modify the properties of native RNase and, thus, might negatively affect its biological activities. Hence, a balance between desired modifications and an excessive unwanted affection of the native properties is mandatory to obtain derivatives accompanied with fruitful enzymatic and biological activities.

\section{Covalently Linked Homo-Oligomeric RNases and Their Biological Activity}

RNases can be artificially associated by exploiting cross-linking reactions with various bifunctional or multifunctional reagents. The most used cross-linkers are mentioned below. This involves especially RNase A and RNase 1, and will be accompanied with the description of the positive or negative rebounds on the relative catalytic and/or the antitumor activities of the products obtained:

(i) Diimidoesters or dialdehydes (Figures 1A-C), i.e., bifunctional cross-linkers, can react with the Lys residues of a protein. These reagents display two terminal reactive groups separated by a variable number of unreactive methylene $\left(-\left(\mathrm{CH}_{2}\right)_{\mathrm{n}^{-}}\right)$spacers. As concerns RNase A, its reactions with dimethyl-adipimidate, dimethylpimelimidate or, especially, dimethyl-suberimidate, i.e., reagents displaying spacers with different " $\mathrm{n}$ " values (Figure 1A), allow differently sized stable dimers or oligomers $(171,178)$ to be formed, often accompanied 


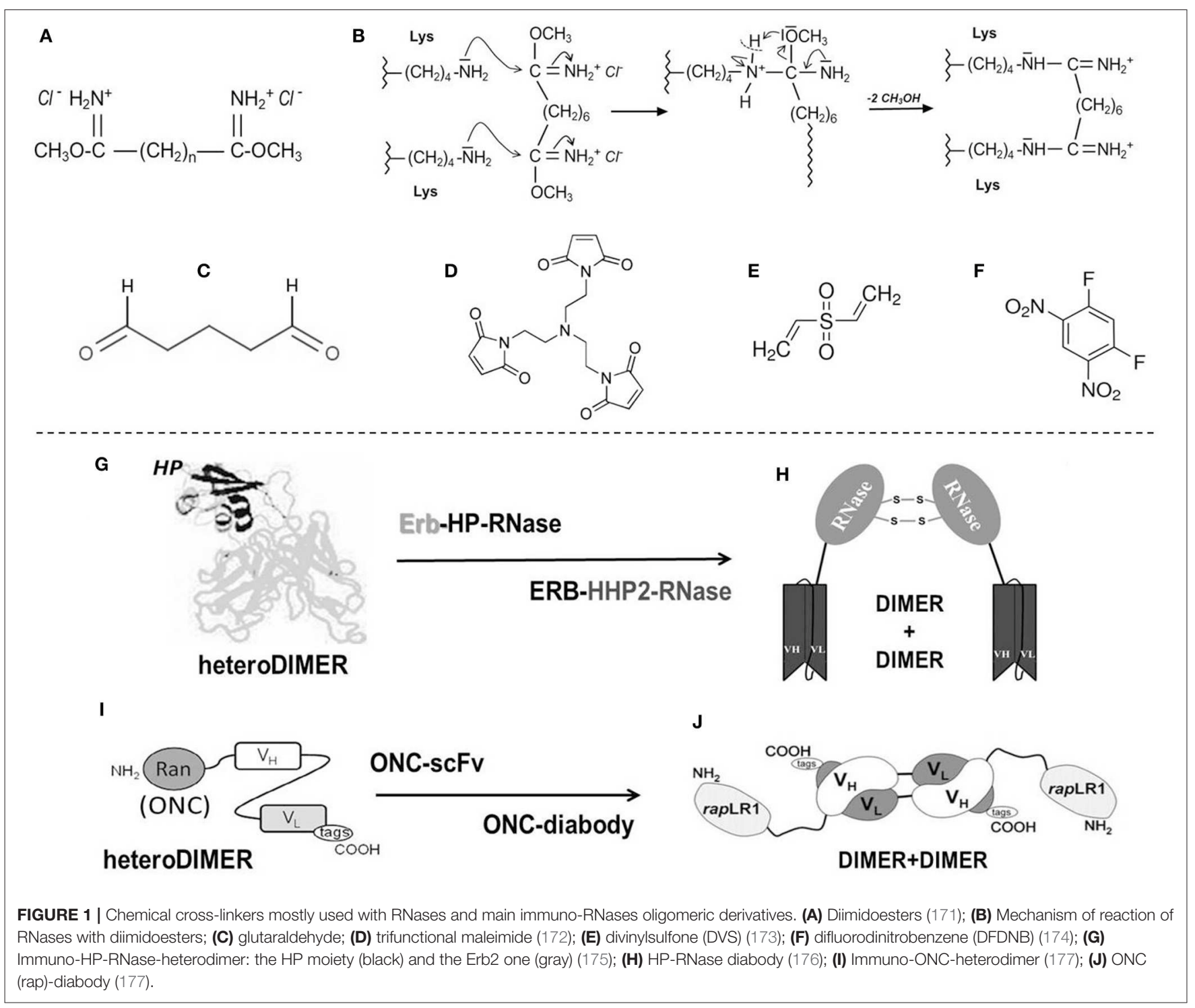

with higher enzymatic activity than the native monomer. Cross-linkers are advantageous to produce protein homooligomers or, alternatively, a cationized and thus more cytotoxic complex, by adding bulky amines or polyamines through the covalent mediation of the diimidoester (179181). The cross-linking can be reversible if the spacer contains a disulfide bond that becomes scissile once the cytosolic reducing environment is reached (182). The reactivity of the Lys nucleophilic residues for the two imides of the cross-linker (Figure 1B) can be more efficiently controlled than with dialdehydes like glutaraldehyde (Figure 1C), and this allows the processed protein to maintain its overall charge unmodified $(171,180)$. An important undesired limitation is represented by the susceptibility to the cross-linker of the active site Lys residue unless it is not protected by phosphate, thus driving toward a percentage of inactive products $(171,183)$.
However, upon properly tuning the reaction conditions, amounts of RNase A dimers characterized by enzymatic and cytotoxic activities definitely higher than native RNase A can be produced $(184,185)$. Again, beyond 20\% yield of active RNase A dimers, dimethyl-suberimidate (Figure 1B) allowed the formation of amounts of covalently linked trimers and traces of higher-order oligomers, all characterized by a relevant cytotoxic activity against cells of the uterus cervix squamous carcinoma (183). Beyond polyamines, RNases can be complexed also with differently sized PEG moieties: indeed, a RNase 1 PEG-derivative is known to inhibit tumor growth in mice (186), while PEG-conjugated RNase A oligomers are cytotoxic against transplanted melanoma in mice as well (187).

(ii) To obtain active RNase oligomers, the bifunctional Nsubstituted maleimide derivatives displaying spacers of variable length are certainly useful (182). These reagents 
induce the cross-linking between a free Cys sulfhydryl and the maleimide to form a reversible adduct if the spacer contains a scissile disulfide bond. The presence of a protein free $-\mathrm{SH}$ group is mandatory to make this crosslinking productive. Unfortunately, RNases do not display free cysteines, and, consequently, the reaction can occur only upon introducing a free Cys residue upon mutagenesis (172). Maleimides can also be trifunctional (Figure 1D), or even more, in this way producing covalently linked trimers and/or larger oligomers. Indeed, the group led by Raines succeeded in obtaining many trimers by coupling cysteinefree RNase A, RNase 1, BS-RNase, or ONC mutants with tris( $N$-maleimidoethyl)amine (172). For all these RNases except for ONC, many mutants displaying a Cys in spite of the Gly88 residue were produced. The mutation of G88 of the wild type is required because this residue allows the proper accommodation of a RNase molecule into the RI cavity to form the already mentioned tight RNase-RI complex $(152,153)$. Instead, since ONC lacks Gly88, the S72C-ONC mutant was produced to allow the formation of the trimer upon cross-linking the protein with the trifunctional maleimide. All RNase trimeric adducts but the ONC one increased their antitumor activity, either in vitro or in mice, with respect to their inactive or less active wt-monomers. Only the trimeric S72C-ONC showed instead to be less cytotoxic than its definitely active wtONC monomer (172). However, the advantage to obtain a bulky ONC trimeric derivative resides on its very probable steric inability to be filtered by the kidneys' glomeruli and, as a consequence, on its increased circulating halflife. Indeed, this may represent a crucial advantage in the perspective to use these products in cancer therapy, considering that the monomeric wt-ONC displayed renal toxicity in vivo, although this undesired effect was reversible upon discontinuing the treatment (188).

(iii) Zero-length dimerization: RNases dimers or oligomers can be formed also upon interaction with carbodiimides $\left(\mathrm{R}_{1}-\mathrm{N}=\mathrm{C}=\mathrm{C}-\mathrm{R}_{2}^{+}\right)$, i.e., dehydrating molecules, such as $N$-(3-Dimethylaminoisopropyl)- $N^{\prime}$-ethylcarbodiimide

(EDC), that can induce the formation of a "zero-length" dimer(s) or larger oligomer(s) characterized by isopeptide bond(s) involving the side chain of the amino group of Lys and the carboxylate group of Asp or Glu residues (189). These reagents can covalently fix previously formed oligomeric aggregates and contemporarily avoid unwanted charge modifications or insertions of chemicals in the protein complex. Supramolecular RNase zerolength adducts can be produced also by heating the protein up to $85^{\circ} \mathrm{C}$ under vacuum (190). This method allowed RNase A to form novel isopeptide bonds between Lys and Glu or Asp residues upon inducing heat-vacuum dehydration. This condensation reaction affects principally, but not exclusively, the RNase A E9 and K66 residues $(190,191)$. However, these derivatives showed a definitively reduced enzymatic activity and inactivity against cancer cells unless they were strongly cationized with polyspermine. This is probably due to the excessive number, at least three, of the affected Lys residues and, thus, by the scarce specificity of the cross-linking reaction that drives toward a mixture of heterogeneous products (191). However, it must be mentioned that the strong cationization allowed the other RNase adducts to gain cytotoxicity but also aspermatogenic effects $(181,192-194)$.

(iv) More recently, oligomers have been produced also upon mixing at $37^{\circ} \mathrm{C}$ RNase $A$ with metallic derivatives commonly used as chemotherapeutic agents, such as cisplatin, or also carbo- or oxaliplatin $(195,196)$. The yield of RNase A-cisplatin oligomers remarkably increases with the cisplatin/protein ratio (195), while with the other Pt adduct yields are definitely lower (196). Unfortunately, these adducts are endowed with scarce ribonucleolytic activity and lack cytotoxicity principally because the catalytic H119 residue is directly involved in the linking with the metallic moiety $(195,196)$. Hence, this result helps to explain why cisplatin and/or similar adducts display a reduced efficacy and undesired side-effects in therapy: in fact, this is because they very probably affect proteins, such as here RNase A, or in vivo serum albumin as well, at a higher extent than the desired DNA target.

(v) RNases can be cross-linked also by using the bi-functional cross-linkers divinyl-sulfone (DVS, Figure 1E) or difluorodinitrobenzene (DFDNB, Figure 1F), which are specific for His or Lys residues, respectively $(173,174)$. These cross-linkers lack spacers and can cross-link only residues residing very close to each other, or they can covalently stabilize preformed oligomers. Indeed, they are extremely useful for characterizing the mechanism of formation of noncovalent supramolecular structures produced by BS-RNase, RNase A or ONC (173, 197-200), but they can be used only for analytical purposes because they totally inactivate the resulting products by involving active site residues.

\section{Covalently Linked or Fusion RNases}

\section{Hetero-Oligomers and Their Biological Activities}

(i) Asymmetric bifunctional reagents are certainly useful in overcoming the lack of protein-free Cys residues: in fact, they can covalently link antibodies, or parts of them (light/heavy chains), with proteins, protein domains, toxins or whatever displays biological interest (Figures 1G,I). They can be, on one side, maleimides or succinimides sometimes displaying dithio-derivatives in the spacers, combined in the other terminus with imidoesters, diones, thiones, or 2iminothiolane. One reagent often used to achieve a covalent hetero-dimerization is 1-(3-((2,5-Dioxopyrrolidinyl)oxycarbonyl)phenyl)-1H-pyrrole-2,5-dione (MBS), but many others are available (201). Some of them have been tested with proteins different from RNases (202), but asymmetric reagents have been used to form active heteroadducts involving RNases as well: in fact, ONC displayed a remarkable antitumor activity against breast cancer or 
brain glioma both in vitro or in mice upon its chemical conjugation with Trop-2 (or EGP-1), or, alternatively, with a chlorotoxin $(203,204)$. Again, strong specific anti-tumor effects exerted by both LL2 or anti-CD22 monoclonal antibodies covalently linked to ONC significantly increased the life span of animals displaying non-Hodgkin B-cell lymphoma (205). Some other chemically cross-linked EGFRNase or Immuno-RNase tumoricidal adducts have been produced since the 90 s with RNase A $(206,207)$ or RNase 1 (208). The list of all the mentioned heterocomplexes are reported in Table 1 together with the ones obtained as immuno-fusion products that are discussed hereafter.

(ii) Alternatively, protein engineering permits cloning and expressing fusion homo- or hetero-fusion dimers as well as fusion immuno-protein conjugates (Figures 1G-J). The cDNA encoding the desired RNase is fused with genes of heavy or light single-chain antibodies. The same strategy can be followed with diabodies (Figures $\mathbf{1 H}, \mathbf{J}$ ), which are non-covalent dimers of single chain antibody fragments $(\mathrm{scFv})$ consisting of variable regions of heavy and light chains $\left(\mathrm{V}_{\mathrm{H}}\right.$ and $\mathrm{V}_{\mathrm{L}}$ ) connected by a small peptide linker $(175,201)$. If desired, additional peptide spacers of various lengths and nature can be inserted between the proteins $(210,218,222)$. In this way, a natural covalent link binds the two proteins, thus permitting the expression of the complete adduct without requiring subsequent chemical modifications. Again, in some cases, as it is for diabodies, the hetero-dimeric immune-RNase adduct has been considered as a new entity that can be further dimerized to form a more active tetramer, as it was performed with both RNase 1 and ONC (Figures 1H,J) $(176,177,216)$. Additionally, a fusion protein composed of two ONC molecules, each fused to the $\mathrm{N}$-terminus of the $\mathrm{V}_{\mathrm{L}}$ of an anti-CD74 humanized antibody, was demonstrated to exert an excellent therapeutic efficacy against $\mathrm{CD}^{+} 4^{+}$tumors either in vitro or in vivo (217).

Following these strategies, several Immuno-RNase or Immunotoxin-RNase complexes have been produced and used as anticancer agents $(175,228)$ also with RNase A. Instead, the group of D'Alessio and De Lorenzo chose to couple human RNase 1 with the human anti-ErbB2 (Figure 1G) $(175,210,211,229)$. The resulting heterodimeric ERB-hRNase adducts showed to be definitely more cytotoxic against breast cancer and induced less resistance and cardiotoxicity than a humanized anti-ErbB2 monoclonal antibody used as a chemotherapeutic agent (175). Furthermore, the tetrameric adduct, i.e., the dimer of the hetero-dimer, called ERB-HHP2RNase, was displayed to be even more cytotoxic than the simple ERB-hRNase adduct (176). Again, some RNase 1 mutants designed to evade RI, and fused to a scFv fragment specific for CD7, reduced the viability of human T leukemic cells (133). More recently, an anti-nucleolin(NCL)-immunoRNase 1 derivative was displayed to be active against triple-negative breast cancer not responding to treatments available so far (212).

The protein-fusion technique has been applied also to ONC to conjugate and express it with many diverse adducts (Figures 1I,J), such as various antibody fragments, human serum albumin, dengue virus-derived peptide, and more recently with the N-terminal domain of transferrin $(177,216,218,219,221$, 230). All these adducts displayed augmented cytotoxicity in vitro against many cancer cells, and in some cases also in mice $(177,218)$. This augmented activity was often accompanied with a lower propensity to undergo renal filtration, as indicated by the results obtained with membranes mimicking the kidney glomerular barrier. Then, another crucial advantage offered by human Immuno-RNases over microbial or plant immunotoxins is the lack of immunogenicity or of non-specific binding and toxicity that usually also affects normal cells. These undesired events drove in some cases even toward fatal events during clinical trials (231). Indeed, De Lorenzo and D'Alessio clarified that the immune-RNase 1 fusion proteins were not only nontoxic outside the tumor cells but also non-immunogenic (228). Again, as reported in Table 1, the protein-fusion strategy against cancer has been used many other times with RNase 1 (213-215) and ONC (220), but also with BS-RNase (226) and EDN (225), producing cytotoxic derivatives. Also Immuno-ANG derivatives have been produced, and the effects on their cytotoxic activity induced by proper ANG mutations (223) or by different linkers introduced in the supramolecular adducts have been compared (222). Again, ANG was driven also toward a diabody-conjugated dimer that was revealed to be definitely more cytotoxic than the monomer (224). Notably, bacterial barnase and fungal RNase T1 have also been derivatized as immunotoxins to become capable of being internalized in cancer cells and exert a remarkable cytotoxic activity (87-89, 227). Finally, in the last decade, RNase A has also been dimerized by cloning and expressing it as a tandem derivative in this way:

Monomer1-C-term-peptide linker-N-term-Monomer2

Contrarily to the inactive monomer, this fusion-stabilized RNase A derivative became definitely cytotoxic against K562 human leukemia cells (209), although it was revealed to be 1:1 complexed with RI (232). This apparently contradictory result could be explained by considering that each RNase A fusion moiety contains one active site, and one of them could be oriented in a way to actually exert its catalytic and cytotoxic actions. To this regard, we underline that the structure of the fusion RNase A-RNase A derivative (see Figure 3B) is not in contrast with this explanation $(209,232)$. All the fusion-produced immuno-derivatives here mentioned are listed in Table 1. Again, many reviews have been focused on the selective cytotoxic action of Immuno-RNases against tumor cells $(108,175,238)$, as it is for the recent and updated one of Jordaan et al. (239).

\section{Non-covalent RNase Oligomers}

Protein oligomerization can also occur non-covalently, either as a natural or an artificial event: indeed, natively monomeric proteins can undergo dimerization or an even larger oligomerization degree. This may occur as a sort of post-translational event that can switch between active and inactive products. Many reports analyzed the features of this event involving many proteins $(169,170,240)$. In the following paragraphs, we will instead focus our attention on the mechanism mainly followed by RNases to self-associate 
TABLE 1 | Chemically linked or recombinantly fusion-produced antitumor-active secreted immuno-RNases.

\begin{tabular}{|c|c|c|c|c|c|}
\hline $\begin{array}{l}\text { Immuno-RNase } \\
\text { conjugate }\end{array}$ & $\begin{array}{l}\text { Chemical/fusion } \\
\text { conjugation }\end{array}$ & Ligand = linker/spacer & Diabody Y/N & $\begin{array}{l}\text { Cell/target and/or human cancer } \\
\text { counteracted }\end{array}$ & References \\
\hline Transferrin(Tf)-RNase A & Chemical & Peptide & $\mathrm{N}$ & Tf-Receptor Leukemia & (108) \\
\hline scFv CD5-RNase A & Chemical & $\begin{array}{l}\text { Succinimidyl-pyridyl-thiopropionate } \\
\text { (SPDP) }\end{array}$ & $\mathrm{N}$ & $\begin{array}{l}\text { K562 and Jurkat-Leukemia; } \\
\text { U251-glioblastoma cell lines }\end{array}$ & $(206)$ \\
\hline RNase A-RNase A tandem & Fusion & $(\mathrm{SG})_{3} \mathrm{~S} / \mathrm{SGRSGRSG} / \mathrm{GP}_{\mathrm{n}} \mathrm{G}$ & $\mathrm{N}$ & K-562 leukemia cells & (209) \\
\hline EGF-RNase 1 & Chemical & $\begin{array}{l}\text { Succinimidyl-pyridyl-thiopropionate } \\
\text { (SPDP) and 2-iminothiolane (2-IT) }\end{array}$ & $\mathrm{N}$ & Many cancer cell lines & (208) \\
\hline scFv-ErbB2-RNase 1 & Fusion & GSPEFM peptide & $\mathrm{N}$ & $\begin{array}{l}\text { SKBR3 and MDA-MB453 breast } \\
\text { cancer cells; } \\
\text { A431 epidermal carcinoma cells }\end{array}$ & (210) \\
\hline scFv-Erb-hcAb-RNase 1 & Fusion & AAASGGPEGGS peptide linker & $\mathrm{N}$ & $\begin{array}{l}\text { SKBR3 and MDA-MB453 breast } \\
\text { cancer cells; } \\
\text { A431 epidermal carcinoma cells }\end{array}$ & $(211)$ \\
\hline AntiNCL scFv4LB5-RNase1 & Fusion & $\begin{array}{l}\text { SGGGGSGGGGSGGS linker } \\
\text { AAASGGPEGGS spacer }\end{array}$ & $\mathrm{N}$ & $\begin{array}{l}\text { MDA-MB-231/436, BT549 breast } \\
\text { cancer cells; } \\
\text { SW } 620 \text { colon adenocarcinoma cells; } \\
\text { In vivo nude mice MDA-MB-231 triple } \\
\text { negative breast cancer }\end{array}$ & (212) \\
\hline FGF Nterm-RNase 1 & Fusion & LPALPEDGGS peptide linker & $\mathrm{N}$ & Many cell lines & $(213)$ \\
\hline IL2-RNase 1 & Fusion & Not specified & $\mathrm{N}$ & $\begin{array}{l}\text { MJ, OKM, and MOLT-3 leukemia cells } \\
\text { lines }\end{array}$ & $(214)$ \\
\hline $\begin{array}{l}\alpha \mathrm{CD} 30 \text { scFv-RNase1-Fc } \\
\alpha \mathrm{CD} 30 \text { scFv-Fc-RNase1 }\end{array}$ & Fusion & AAASSG peptide linker & $\mathrm{N}$ & $\begin{array}{l}\text { Karpas-299 Lymphoma cell line } \\
\text { HEK } 293 \text { T human embryo } \\
\text { kidney cells }\end{array}$ & $(215)$ \\
\hline anti-CD22 scFv SGIII-ONC & Fusion & GGGGS peptide & Y & $\begin{array}{l}\text { CA46 + Raji Burkitt lymphoma cells } \\
\text { Daudi lymphoma cells } \\
\text { Jurkat leukemia cells; } \\
\text { tRNAs }\end{array}$ & (216) \\
\hline Anti-EGFR-scFv IZI08-ONC & Fusion & GGGGS or $\left(G_{4} S\right)_{3}$ peptides & Y & $\begin{array}{l}\text { A431/Raj//HNO and FaDu } \\
\text { oro-pharyngeal/CAL27 tongue/MCF7 } \\
\text { breast cell lines + } \\
\text { In vivo A431 Nude mice }\end{array}$ & $(177)$ \\
\hline 2L-ONC-hLL1- $\gamma 4 \mathrm{P}$ (S228P) & Fusion & $\left(\mathrm{G}_{4} \mathrm{~S}\right)_{3}$ peptide linker & $\mathrm{N}$ & $\begin{array}{l}\text { Daudi/Raji and MC/CAR lymphocytes } \\
+ \text { SCID or BALB/c in vivo mice }\end{array}$ & $(217)$ \\
\hline 4D5MOCB-Album-o-ONC & Fusion & $\begin{array}{l}\text { Circular }<\text { RKRRC }_{S-S} \text { CAEAE }< \\
\text { peptide }\end{array}$ & $\mathrm{N}$ & $\begin{array}{l}\text { HT29 Colorectal carcinoma and } \\
\text { A375 melanoma cell lines }\end{array}$ & (218) \\
\hline $\begin{array}{l}\text { Anti-EGFR scFv } \\
\text { IZI08-Dengue-ONC }\end{array}$ & Fusion & $\begin{array}{l}\text { MVDRGWGNGCGLFGKGGIV } \\
\text { Dengue peptide }\end{array}$ & $\mathrm{N}$ & $\begin{array}{l}\text { HNO97/HNO211/HNO410 oral, } \\
\text { A431 epidermal, and MCF7 breast } \\
\text { carcinoma cells }\end{array}$ & (219) \\
\hline ONC-DV3 & Fusion & PFV linker & $\mathrm{N}$ & $\begin{array}{l}\text { MDA-MB-231/MCF7 breast } \\
\text { PC-3M-1E8/PC-3M-2B4 prostate } \\
\text { PG-BE1/PG-LH7 lung cancer }\end{array}$ & $(220)$ \\
\hline $\begin{array}{l}\text { Transferrin } \\
\text { Nterm(TFn)-ONC }\end{array}$ & Fusion & $\left(\mathrm{G}_{4} \mathrm{~S}\right)_{3}$ peptide linker & $\mathrm{N}$ & $\begin{array}{l}\text { HepG2 hepatocarcinoma } \\
\text { HeLa cervix carcinoma cell lines }\end{array}$ & $(221)$ \\
\hline
\end{tabular}


TABLE 1 | Continued

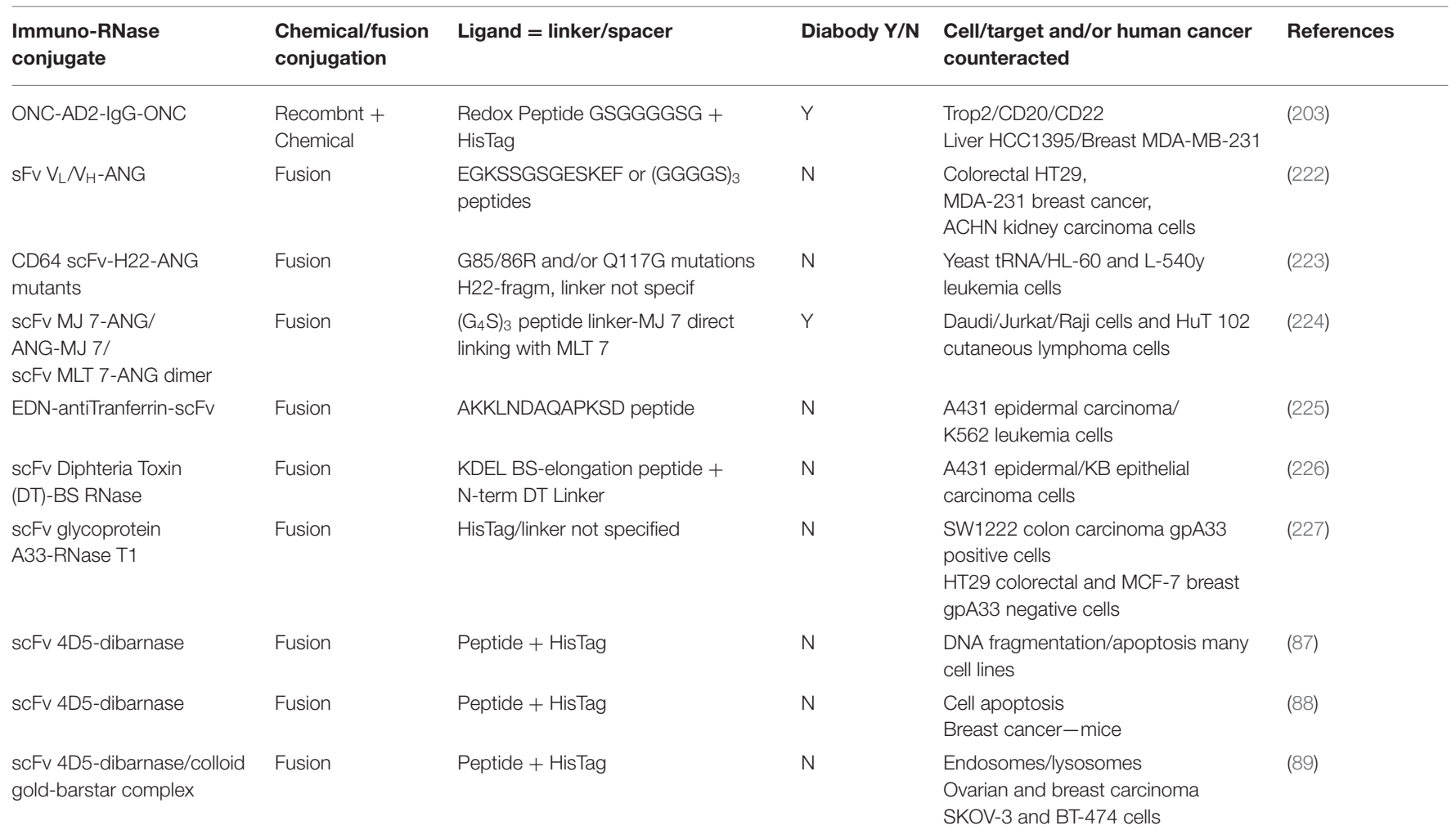

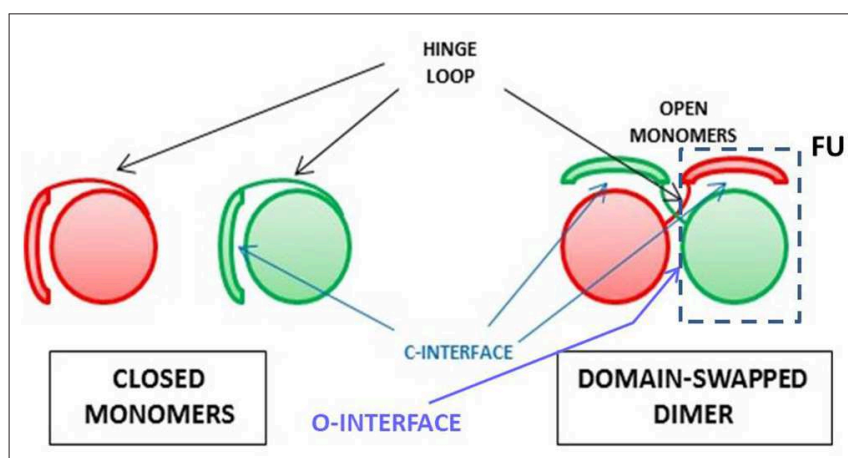

FIGURE 2 | Scheme for the 3D-DS protein association mechanism. The closed interface present in the native monomer and reconstituted in the domain-swapped dimer, and the open interface(s) forming only in the dimer are indicated (241), as well as the composite functional unit (FU) (235) of the dimer inside the dashed line.

without being covalently cross-linked, i.e., the one called three dimensional domain swapping (3D-DS), whose schematic picture is shown in Figure 2.

\section{RNases and the Oligomerization Through Three-Dimensional Domain-Swapping (3D-DS)}

The non-covalent self-association of RNases is mainly ascribable to the 3D-DS mechanism, as reported in Table 2. Firstly defined and described by Eisenberg et al. (241, 242), and affecting many proteins $(235,243,244)$, this mechanism has been deeply analyzed also by many other scientists (241, 244-247). 3D-DS partially violates the Anfinsen dogma which states that the AA sequence induces a protein to find a unique folding (10): in fact, the flexible loops of a protein (in particular, for RNase A, residues 16-22 and 112-115) can instead adopt variable conformations, thus occupying more than one energy minimum (241). This allows the domains linked to the protein flexible parts to adopt different orientations and to undergo a reciprocal exchange of a protomer domain with the equivalent domain of an adjacent subunit. Therefore, a non-covalent dimer, or even larger oligomers, if more than a single flexible loop is present, can be formed $(235,243)$. The domain detached from the native monomer can reconstitute the native protomer contacts in each composite, functional unit (FU) of the oligomer (Figure 2) (235). The novel FU overlaps the native monomer, except for an additional interface(s), whose conformation depend(s) to each particular protein, and that is/are absent in the native monomer (241). The domains involved in 3D-DS are often the protein $\mathrm{N}$ - or C-termini, or both, as it is for some RNases $(235,243)$. Oligomerization is often accompanied in RNases with an increase of their enzymatic and biological activities, or, moreover, with new properties absent in the native monomer. Notably, the 3D-DS mechanism is shared by many other proteins, like for example cytochrome C (248), and above all by several amyloidogenic proteins, such as human prion protein, cystatin$\mathrm{C}$ or also $\beta_{2}$-microglobulin, all self-associating through $3 \mathrm{D}$-DS (249-252). Except for ECP/RNase 3 (46), all known RNases are unable to undergo amyloidosis, although RNase A displays many 
TABLE 2 | List of the most important secreted RNases that spontaneously oligomerize.

\begin{tabular}{|c|c|c|c|c|}
\hline Secreted RNase & Oligomers & 3D-DS* mechanism & Cross-linked oligomers & Cytotoxic activity \\
\hline RNase A & $\begin{array}{l}\text { Dimers/Trimers/Tetramers up to } \\
\text { Tetradecamers traces }\end{array}$ & Y: N + C-swap & $\begin{array}{l}\text { Native with bifunctional linkers } \\
\text { Mutants with S-S bonds }\end{array}$ & Oligomers: debated \\
\hline BS-RNase (dimeric) & $\begin{array}{l}\text { Dimer } \\
\text { Tetramers/Hexamers/Octamers }\end{array}$ & $Y: N+C$ swap & Natural S-S bonds & Yes \\
\hline RNase 1 & Dimers & $\begin{array}{l}\text { Y: N-swap } \\
\text { in mutants }\end{array}$ & $\begin{array}{l}\text { Mutants with S-S bonds } \\
\text { (HHP/HHP2-RNase 1) }\end{array}$ & Oligomers: Yes \\
\hline ANG & Not detected & Not detected & Only Immuno-derivatives & Oligomers: Yes \\
\hline ONC & Dimer & Y: N-swap & Only in Immunoderivatives & $\begin{array}{l}\text { Monomer and Dimer: } \\
\text { Yes }\end{array}$ \\
\hline Barnase & Trimer & Y: N-swap & Immunoderivative & Yes \\
\hline Binase (dimeric) & Only the native dimer & Not detected. & Not detected & Yes \\
\hline RNase T1 & Dimer mutant & Y & Immunoderivative & Oligomeric: Yes \\
\hline
\end{tabular}

*3D-DS, three-dimensional domain swapping.

amyloid-prone segments. However, the presence of 3D-DS was not proven in ECP (253). Indeed, it is worth noting that residue(s) insertion(s) was incurred by the RNase A loops, allowing the 3D-DS to occur make it capable of forming amyloid-like domainswapped fibrils $(254,255)$.

The non-covalent aggregation has been known to occur in RNase A and BS-RNase since the 60s (256-258), affecting the catalytic activity against RNA substrates. The 3D-DS involvement had already been hypothesized in 1962 by Moore et al. on the basis of the characterization of RNase $\mathrm{S}$ deriving from RNase A limited proteolysis that cleaves the $\mathrm{N}$-terminal domain (residues $1-20)$ from the protein core $(259,260)$. RNase A aggregation was therefore already ascribed to a reciprocal exchange of the protein $\mathrm{N}$-termini consequent to their detachment from the protein core (256). The actual presence of 3D-DS in RNases was then detected for BS-RNase only in 1993 by Mazzarella et al., while for RNase A in 1998 by Liu et al. $(19,233)$.

In the next paragraphs we list and discuss the main features of the domain-swapped dimers and oligomers of various pancreatic-type RNases, above all RNase A, BS-RNase and RNase 1 , and recently also ONC, to highlight the related biological consequences. We start with RNase A, but in each paragraph comparisons within different RNase variants will be present.

\section{RNase A}

Natively monomeric, $13.7 \mathrm{kDa}$ RNase A (Figure 3A) can non-covalently self-associate by interacting with the substrate (261), but it can also oligomerize upon being subjected to lyophilization from $40 \%$ aqueous acetic acid solutions (256) or to thermal incubations in different solvents at very high protein concentration (262). Following these two protocols, RNase A produces domain-swapped dimers, trimers, and larger oligomers $(115,198,235,237)$. Oligomerization occurs through the aforementioned 3D-DS mechanism involving both $\mathrm{N}$ - and/or C-terminal domains of the protein $(115,235)$, thus producing different relative amounts of $\mathrm{N}$ - or $\mathrm{C}$-swapped oligomers as a function of the particular protocol applied (256). Oligomers can be separated with cation-exchange chromatography, being the C-swapped species endowed with a higher basic charge exposure than the N-swapped ones (263). NMR showed that RNase A is chiefly denatured except for disulphides in $40 \%$ acetic acid, while it refolds properly, with the exception of the 3DDS-inducing flexible loops only when, after lyophilization, it is redissolved in a "benign" buffer, such as phosphate (264). This permits the formation of many different RNase A oligomers, up to traces of tetradecamers (265). The structures of the RNase A $\mathrm{N}$ - and C-termini-swapped dimers (called $\mathrm{N}$-dimer or $\mathrm{N}_{\mathrm{D}}$ and $\mathrm{C}$-dimer or $\mathrm{C}_{\mathrm{D}}$, respectively), and of a cyclic C-swapped trimer, $\mathrm{C}_{\mathrm{T}}$, have been solved (Figures 3C,D,F) (233, 234, 236). Additionally, models based on experimental data have been built for a $\mathrm{N}+\mathrm{C}$-swapped-trimer, i.e., displaying the swapping of both enzyme termini $\left(\mathrm{NC}_{\mathrm{T}}\right.$, Figure $\left.3 \mathrm{E}\right)$, and for many other $\mathrm{N}+\mathrm{C}$-swapped tetramers (Figures 3G-J) or larger multimers $(197,235,237)$. The most abundant species detectable is certainly the C-dimer that approaches $20 \%$ yield, while its amount deriving from thermal incubations is lower $(197,262)$. DVS or DFDNB (Figures 1E,F) crosslinking analysis confirmed that the protein self-associates through 3D-DS involving both RNase A N- and/or C-termini in all the oligomers, up to hexamers, analyzed (197, 198). The structural determinants governing RNase A 3D-DS oligomerization have been deeply investigated (266). In detail, the polarity of both RNase A N- and C-termini affects both the swapping propensity and the oligomers' stability (267), while either reducing conditions or deamidation events affecting many Asn residues reduce the tendency of RNase A aggregation through 3D-DS $(268,269)$. Importantly, the cis configuration of the X-Pro114 peptide bond present in the loop preceding the C-terminus of RNase A, RNase 1 or also BS-RNase hinders the tendency of the same terminus to be swapped $(266,270$, 271). Consequently, harsh conditions are required to switch the mentioned bond from cis to trans and let the formation of remarkable amounts of RNase A C-dimer (262). In this context, it is quite surprising that about $20 \%$ of RNase A C-dimer was detected in the endoplasmic reticulum of pancreatic exocrine cells, although subsequently the dimer failed to be secreted (272). Also, glycosilation can hinder RNase 3D-DS self-association, as was demonstrated by the Asn34 N-glycosilated RNase A form called RNase B (16). Many reports indicate the actual reciprocal 


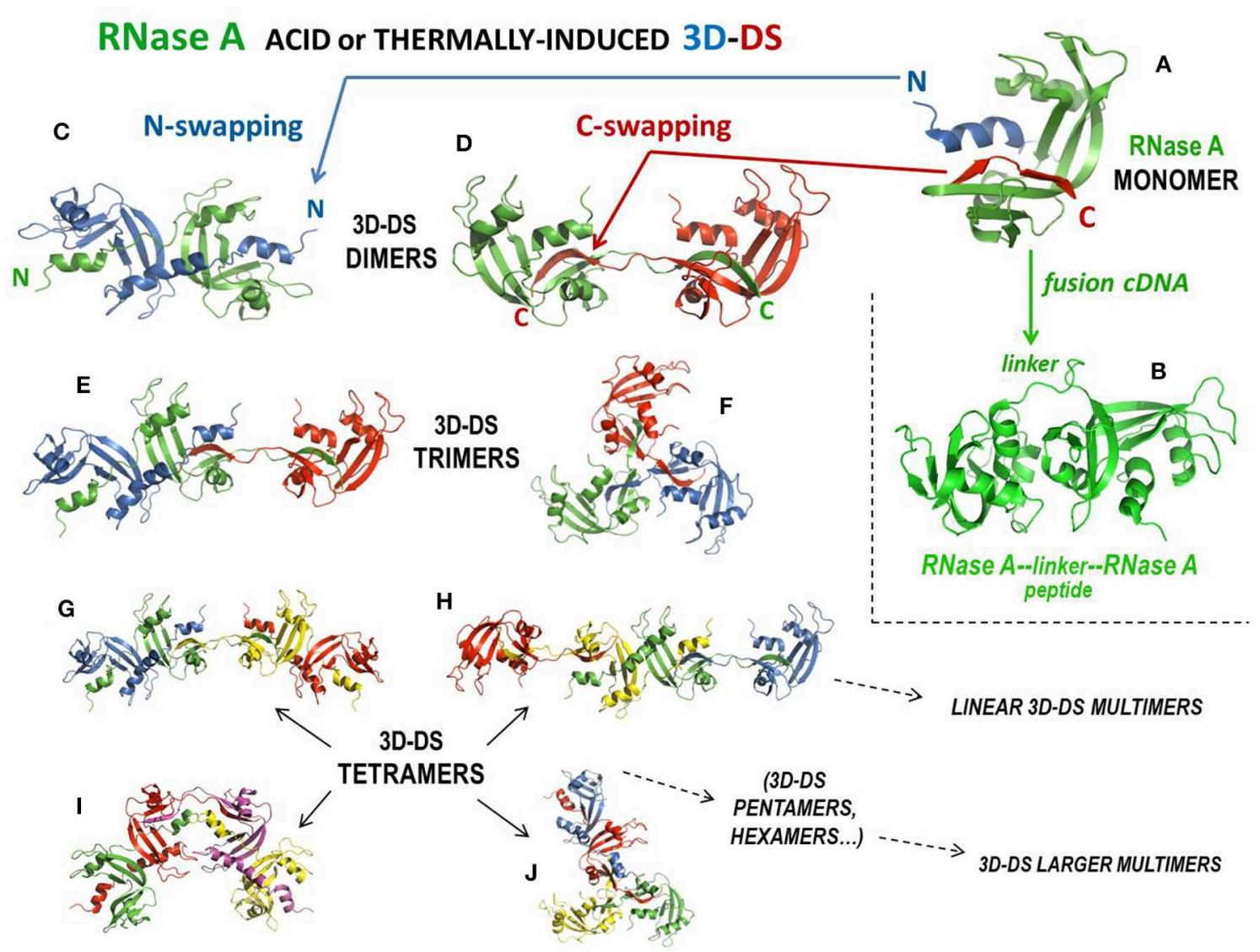

FIGURE 3 | Structures of RNase A, of its tandem dimer, and of its domain-swapped oligomers. (A) RNase A; (B) covalent tandem dimer (232); (C) crystal structure of the N-swapped dimer, $\mathrm{N}_{\mathrm{D}}$ (pdb 1A2W) (233); (D) crystal structure of the C-swapped dimer, $\mathrm{C}_{\mathrm{D}}$ (pdb 1FOV) (234); (E) N + C-swapped trimer model, NC

$(197,235,236) ;(\mathbf{F})$ crystal structure of the totally C-swapped cyclic trimer, $\mathrm{C}_{\mathrm{T}}$ (pdb 1JS0) (236); (G) N + C + N-tetramer linear model (197, 235); (H) C + N + C-tetramer linear model (197, 235), (I) N + C + N-tetramer bent model (237); (J) N + C + C + C-tetramer model (235).

influence of the $\mathrm{N}$ - and C-termini in their swapping behavior (16, 267, 273, 274), in line with RNase S (259): indeed, this derivative dimerizes upon acidic lyophilization, but less than RNase $\mathrm{A}$ and obviously only through the swapping of its C-terminus (275).

All 3D-DS RNase A oligomers increase their enzymatic activity against ds-RNA substrates, or vs. DNA:RNA hybrids, with respect to the native monomer $(258,263)$ : the increase is directly proportional to the size of the oligomers, and moreover, within the same type of oligomer, i.e., within $\mathrm{N}_{\mathrm{D}}$ vs. $\mathrm{C}_{\mathrm{D}}$, or $\mathrm{NC}_{\mathrm{T}}$ vs. $\mathrm{C}_{\mathrm{T}}$, etc. (see Figures $\mathbf{3 C}-\mathbf{J}$ ), the highest enzymatic activity is displayed by the species containing more C-swaps than $\mathrm{N}$ swaps, because the former species expose a higher basic charge density than the latter ones (263). The antitumor activity of the oligomers has been measured too, obtaining controversial results: a relevant activity always increasing with the basic charge density of the oligomers was displayed against leukemia cells in vitro and in vivo when human melanoma cells were transplanted in nude mice $(116,168)$. Moreover, in similar in vivo experiments, this antitumor activity slightly increased when RNase A oligomers were conjugated with PEG (187). In those cases, both free and PEG-conjugated RNase A oligomers were devoid of embryotoxic activity $(168,187)$. Conversely, the same RNase A oligomers were not active against two human pancreatic tumor cell lines (125). However, the actual antitumor activity of the RNase A oligomers is debated because the two RNase A dimers are known to interact with RI, although with a 1:1 stoichiometry, like the aforementioned tandem RNAse A-RNase A fusion dimer (Figure 3B) that was displayed to be cytotoxic $(167,232)$. It must be underlined, however, that Wang et al. recently reported that RNase A, differently from RNase 1 and ANG, can induce cell proliferation ascribable to an extracellular RNase A interaction with the epidermal growth factor receptor (EGFR), in this way counteracting cytotoxicity as well (276). Hence, from what has been reported, the evaluation of the actual antitumor potential of RNase A species certainly deserves further investigation.

\section{BS-RNase}

As mentioned, BS-RNase is the unique natively homo-dimeric member of the pancreatic-type RNase superfamily because of the two antiparallel disulfides linking the Cys31 residue of one subunit and the Cys32 of the other, and vice-versa (277). These 
two residues are absent in other RNases. However, each BSRNase subunit is composed of 124 AA residues and displays $82 \%$ sequence identity with RNase A (17). Interestingly, native BS-RNase is an equilibrium mixture between two isoforms (Figures $4 A, B)$, one of which $(\sim 70 \%)$ is characterized by the swapping of its $\mathrm{N}$-termini and is represented as $\mathrm{M} \times \mathrm{M}$ (panel $\mathrm{B}$ ), while the other $(\sim 30 \%)$ is unswapped and named $M=M$ (panel A) (278), given that only the two inter-chain C31-C32/C32C31 disulfides permit the dimer formation. This $\mathrm{M} \times \mathrm{M} / \mathrm{M}=\mathrm{M}$ equilibrium has been deeply investigated (282) and partially affects the catalytic activity of the enzyme (278). The role of the inter-subunit disulfides has also been analyzed $(283,284)$, as well as the one of the hinge loop connecting the N-terminus with the protein core. In addition, P19 and L28, as well as R80 residues, have been shown to influence the $\mathrm{M}=\mathrm{M}$ vs. $\mathrm{M} \times \mathrm{M}$ equilibrium (285-287).

The ribonucleolytic activity of the enzymes present in the bovine seminal fluids was firstly described by D'Alessio and Leone in 1963 (288). The responsible agent for this activity was discovered to be BS-RNase, that is definitely more basic and more active against ds-RNA adducts than RNase A (289). This is true also after monomerizing the enzyme by the reduction of the two inter-subunit disulfides (290), thus confirming that the basic charge density, and not the dimeric nature per se, is crucial for a RNase to be active against ds-RNA substrates. Moreover, as reported before, BS-RNase exerts a remarkable antitumor activity $(162,291,292)$, together with immunosuppressive, embryotoxic and aspermatogenic effects $(73,75-77)$. Cytotoxicity is selectively addressed only against malignant cells, also of human origin $(125,293,294)$, and is ascribable only to the $\mathrm{N}$-swapped $\mathrm{M} \times \mathrm{M}$ isoform, while neither $\mathrm{M}=\mathrm{M}$ nor the wt-monomeric derivative are active $(162,164)$. This feature has been ascribed to the ability of only $\mathrm{M} \times \mathrm{M}$ to evade cellular RI: in fact, the cytosolic reducing environment, although breaking the two inter-subunit BS-RNase disulfides, does not monomerize the $\mathrm{M} \times \mathrm{M}$ isoform, whose dimericity survives, although as a non-covalent dimer (NCD), for a sufficient time to exert its cytotoxic action. The unswapped $\mathrm{M}=\mathrm{M}$ isoform instead undergoes monomerization upon losing the two mentioned disulfides and becomes therefore susceptible to the RI blockage (164). The crystal structures of the $M=M$, $\mathrm{M} \times \mathrm{M}$ (Figures $4 \mathrm{~A}, \mathrm{~B}$ ), and NCD isoforms of BS-RNase, as well as of the monomeric derivative, have been solved, in this way clarifying crucial structural features that govern the possibility of this enzyme to exert its biological activities $(19,279,295,296)$.

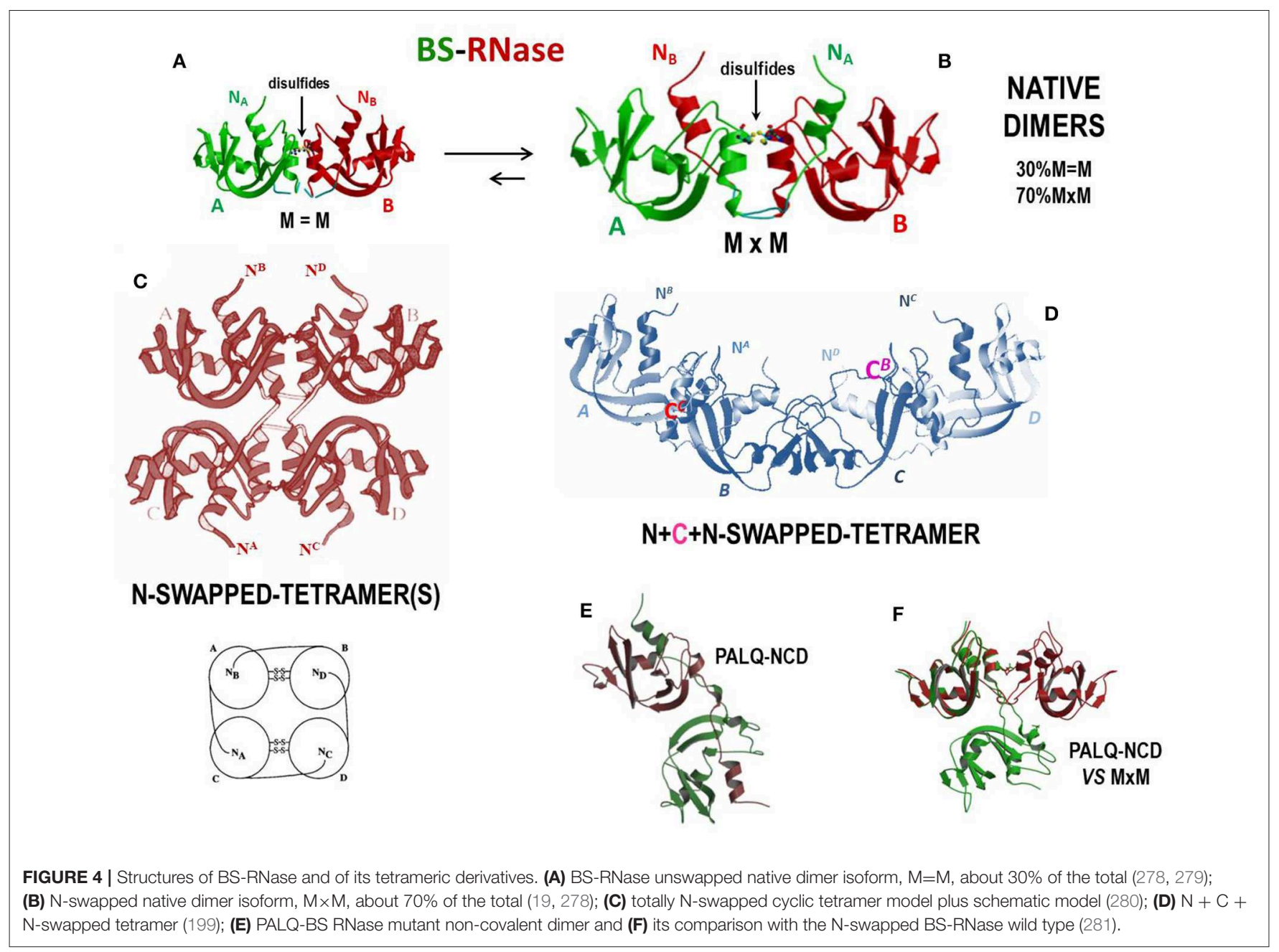


Importantly, the $\mathrm{M} \times \mathrm{M}$ isoform does not vary its conformation upon losing its inter-subunit disulfides and forms NCD only if the P19 and L28 are conserved, because these residues allow NCD to maintain the capability to evade RI (see Figures $4 \mathrm{E}, \mathbf{F}$ ). The P19 and L28 mutations induce instead a dramatic variation in the reciprocal orientation of the two subunits that renders the mutated NCD variant inactive because it becomes susceptible to RI (281). However, mutants of the monomeric BS-RNase derivative designed to evade RI exerted a 30-fold higher cytotoxic activity than the wild-type dimer (292).

As well as RNase A $(269,297)$, BS-RNase easily undergoes Asn67-to-Asp deamidation, an event that is even quicker than for the pancreatic variant (298). However, the acquired negative charge of Asp67 does not affect its cytotoxicity. Additionally, many efforts have been performed to increase the RNase A/BSRNase similarity to make also the pancreatic variant endowed with antitumor activity. To this end, dimerizing RNase A variants built through the introduction of the $\mathrm{K} 31 \mathrm{C} / \mathrm{S} 32 \mathrm{C}$ mutations, in addition to others, was revealed to exert relevant antitumor action against malignant fibroblasts (299, 300), while the cytotoxicity of an engineered RNase A/BS-RNase hybrid displaying a $\mathrm{N}$-swapped dimeric structure was not measured (301).

Interestingly, BS-RNase can also be induced to self-associate upon acetic acid lyophilization. In this way, tetramers, hexamers and even larger oligomers can be formed: two different tetramers forming through the swapping only of their $\mathrm{N}$-termini were hypothesized and modeled by Mazzarella et al. (Figure 4C) (280), while more recently it has been demonstrated that BSRNase can swap also its C-termini, as RNase A does. The Ctermini swapping can occur either in the native dimer, to form a $\mathrm{N}+\mathrm{C}+\mathrm{N}$-swapped tetramer (Figure 4D) (199), or also involve the BS-RNase monomeric derivative to produce a $\mathrm{C}$ swapped dimer structurally similar, but not identical, to the RNase A $C_{D}$ (302). Importantly, BS-RNase oligomers also display enzymatic and cytotoxic activities higher than the native dimer; again, both activities increase with the size of the oligomers and, consequently, with their basic charge density (199). To this regard, many structural, enzymatic and antitumor features of RNase A and BS-RNase oligomeric species are compared and discussed in (117).

\section{RNase 1 or HP-RNase}

Human pancreatic (HP) RNase 1 (Figure 5A) is natively monomeric, but, being 128 AA residues long, it displays a Cterminus elongation of four residues with respect to its bovine homolog RNase A, and it is more basic than it $(266,305)$. This elongation does not affect RNase 1 stability and reduces only slightly its enzymatic activity (306). Moreover, this variant is definitely more active than RNase A vs. ds-RNA substrates (12),

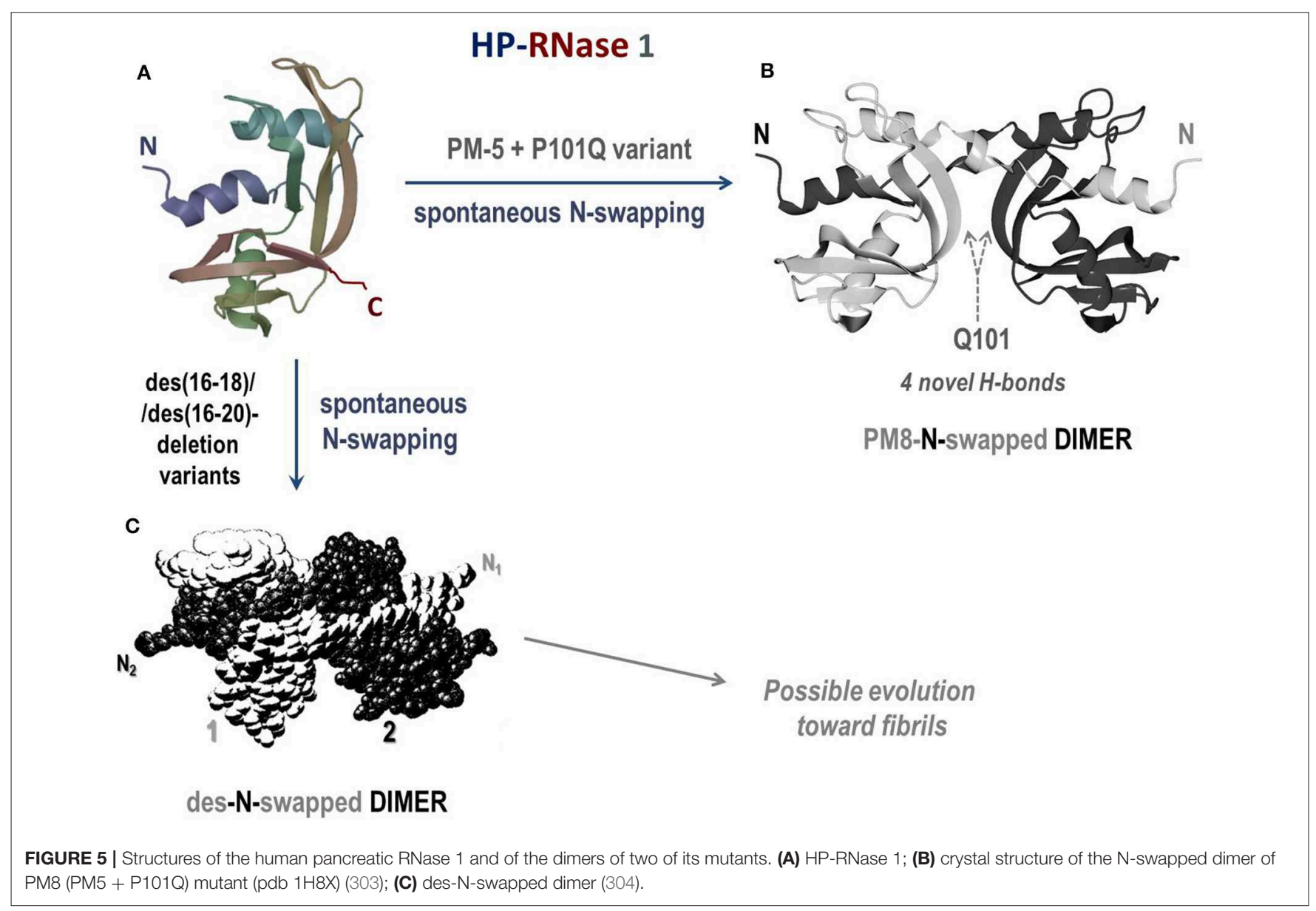


reaching a maximal value at $\mathrm{pH}$ 7.3. This $\mathrm{pH}$ is very close to the one of the blood and definitely higher than 6.5 , the value under which RNase A exerts its maximal activity (12). Therefore, considering the high basicity of its native state, RNase 1 has been mutated to insert, as well as in RNase A (299), two $31+32$ cysteine residues to make it dimerize similarly to BS-RNase: these mutants, named HHP-RNases, displayed a remarkable antitumor activity against several types of malignant cell lines, among which cells from neuroblastoma and rhabdomyosarcoma showed the highest sensibility (307). Indeed, the RNase 1 variant displaying the Cys31 + 32 couple plus the N28L/N34K/E111G mutations, and called HHP2-RNase, exerted a quite high antitumor activity against human thyroid carcinoma-derived cell lines and in vivo when malignant cells were transplanted into nude mice (308). Cytotoxicity was exerted by both swapped and unswapped isomers, contrarily to BS-RNase, and this result was ascribed to the stabilization effect of both the hinge loop and the Leu28 side chain in terms of maintaining the two Cys31/32 residues close to each other (309). More recently, other different Cys31/32 cytotoxic dimeric mutants have been engineered to evade RI, and they were displayed to exert a relevant cytotoxic activity as well (310).

Other RNase 1 mutants able to swap their N-termini have been produced: five-residue mutant (PM5) that makes the RNase $1 \mathrm{~N}$-terminal edge identical to BS-RNase displayed a higher stability than the wild type (311). Moreover, an additional P101Q mutation introduced in this variant allowed RNase 1 to spontaneously dimerize through $3 \mathrm{D}$-DS thanks to the formation of four novel inter-subunits H-bonds (Figure 5B). This additional mutation permits also stacking interactions between the $\beta$-sheets of each protomer to be gained, similarly to what occurs in the RNase $A N_{D}$ (303). Hence, this RNase $1 \mathrm{~N}$-swapped dimer, called PM8, combines the structural determinants of BS-RNase (five mutations in the N-terminus, PM5) with the crucial role of Gln101 detected in the RNase A N-dimer $(233,312)$. However, the structure of this dimer (303) is quite different from both BS-RNase $\mathrm{M} \times \mathrm{M}$ isoform because the Cys31-32 disulfides are absent (19, 233). Again, deletions suffered by the loop connecting the N-terminus to the protein core (des(16-18) or des(16-20)HP-RNase) induced the spontaneous formation of stable dimers forming through the domain swapping of the N-termini (Figure 5C), as confirmed by the DVS cross-linking (304). Interestingly, the des(16-20) HPRNase mutant was recently discovered to form supramolecular structures resembling amyloid-like rod-shaped fibrils (313). The structural features of many dimerizing RNase 1 variants have been deeply analyzed (314), while their antitumor activity has not been investigated so far.

\section{Onconase (ONC)}

Extracted from the Rana pipiens oocytes, ONC is the unique pancreatic-type RNase known to be remarkably cytotoxic in its very stable native monomeric form (Figure 6A) together with the less investigated, but also amphibian, amphinase variant (27). Although being the smallest [104 AA, MW 11.8 $\mathrm{kDa}(28)$ ] pancreatic-type RNase, and being also not highly catalytically active, ONC displays the same catalytic triad (here
$\mathrm{H} 10 / \mathrm{K} 31 / \mathrm{H} 97)$ and catalytic subsites similar to the RNase A ones as well (316). Furthermore, beyond its antitumor effect, ONC displays a prominent antiviral action by upregulating factors that inhibit viral genome replication (317). ONC can penetrate cancer cells because of its high basicity and favorable interaction with the sialic acids moieties present on the malignant cell membranes (318). Then, the crucial step is that ONC evades RI because it lacks the key residues necessary to form a tight complex with the inhibitor (152). ONC can attack tRNAs, as well as other substrates, such as miRNAs, to exert its cytotoxic action (319-321). Thus, at first glance, it would seem unnecessary to produce ONC supramolecular structures to design anticancer therapies (322); in fact, many positive results have been registered with monomeric wt-ONC both in vitro and in vivo against several still incurable tumors, like pleural mesothelioma, human lung, glioma, pancreas and melanoma (27, 323-326). However, the although reversible renal toxicity of ONC discovered upon clinical trials (188) partially cooled down the initial enthusiasms. This somehow alerts to find a way to enlarge the dimensions of ONC moieties to make their filtration at the glomerular barrier more difficult, and increasing its circulating half-life at the same time. Consequently, many fusion immune-ONC derivatives have been successfully built, as we reported in the previous paragraphs and in Table 1 (218). Then, notwithstanding its remarkable stability $\left(\mathrm{T}_{\mathrm{M}} \sim 90^{\circ} \mathrm{C}\right.$ ), ONC has been recently discovered to form a N-swapped dimer upon lyophilization from acetic acid (Figure 6B) (200). Notably, this dimer displayed to be more cytotoxic against pancreatic cancer cells than the corresponding native ONC monomer (200). Unfortunately, ONC can swap only its N-terminus, being the C-terminus locked by the disulfide involving the Cys87 and Cys104 terminal residues. The impossibility to swap more than one domain definitely reduces the protein self-association propensity in general (243), and this is certainly the case of ONC. Moreover, some ONC variants built to unlock its C-terminus were found to be less stable than the native enzyme $(327,328)$. This suggests a negative influence of the free ONC C-terminus in the stabilization of the $\mathrm{N}$-swapped dimer, confirming also for ONC the reciprocal influence of the $\mathrm{N}$ - and C-termini in the 3D-DS event involving RNases (200). Consequently, the unique way known to date to obtain large ONC homo-oligomers useful to escape renal filtration is the use of the aforementioned trifunctional maleimide to produce covalent derivatives (see Figure 1D) (172).

However, and finally, we mention a very recent study that exploited both ONC and RNase A features to build a chimera able to remarkably augment the tendency of the latter mammalian enzyme to undergo 3D-DS oligomerization. This was obtained by substituting in RNase A the 112-115 C-terminal loop, comprising the Pro114 residue, with the shorter loop present in ONC and devoid of this proline key-residue (271).

\section{Microbial Barnase and Binase}

Barnase and binase, both RNase variants of about $12 \mathrm{kDa}$, belong to the RNase N1/T1 microbial superfamily. Importantly, we firstly recall that in the past a mutant of fungal RNase T1 was shown to acquire activity against ds-RNA upon dimerization through 3D-DS (see Table 2) (329). Conversely, 


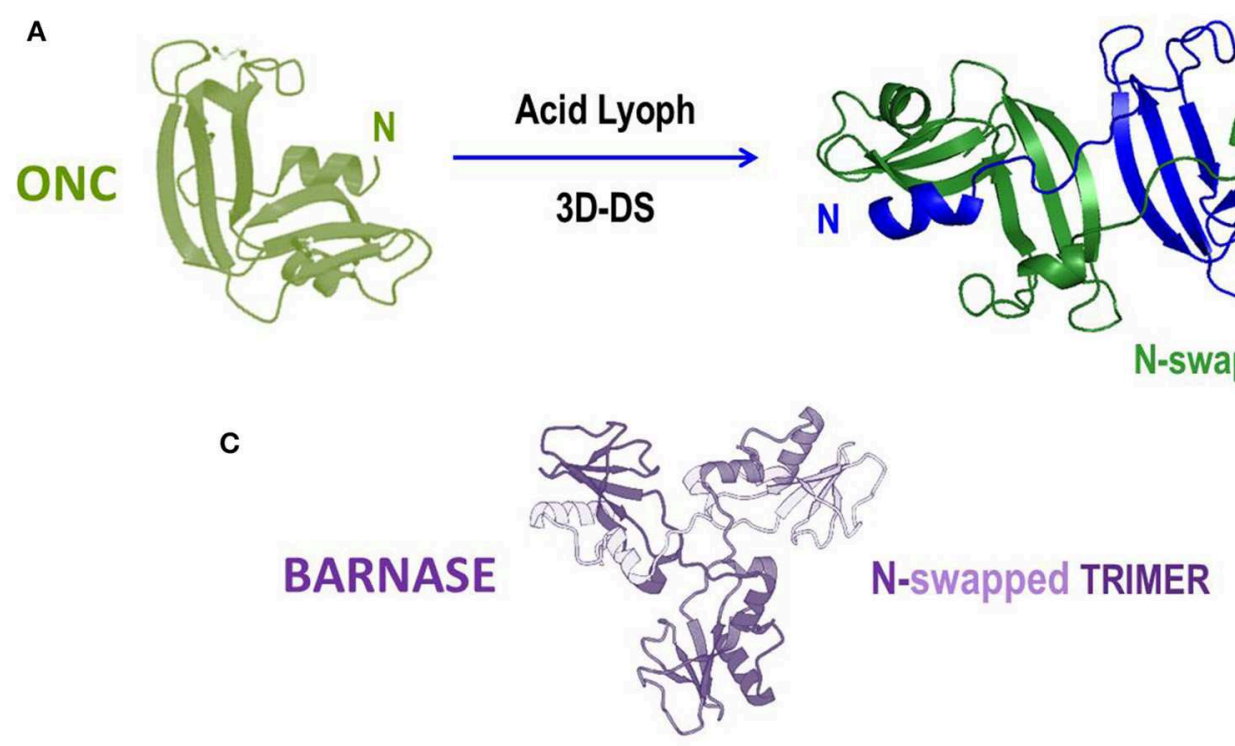

D

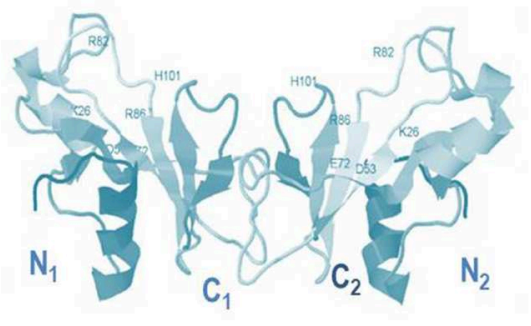

BINASE

UNSWAPPED DIMERS MODELS

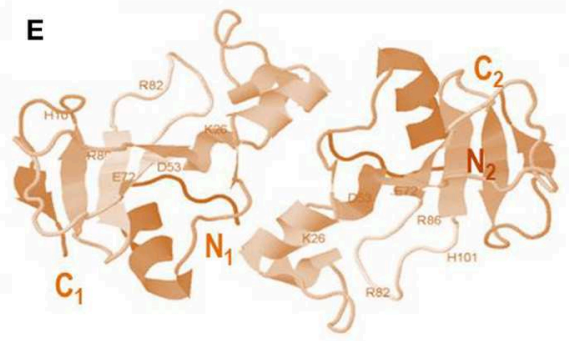

FIGURE 6 | Structures and models of non-mammalian RNases and of their oligomers. (A) Amphibian onconase (ONC); (B) N-swapped ONC dimer model (200); (C) crystal structure of the $\mathrm{N}$-swapped cyclic trimer of bacterial barnase (pdb 1YVS) (315); (D,E) two alternative models for the bacterial natively dimeric unswapped binase, stabilized by electrostatic interactions at the subunits' interface (90).

the wt-RNase $\mathrm{T} 1$ is not cytotoxic, being unable to enter the cells if it is not pre-incorporated into a HVJ cell-penetrating envelope vector (330). Then, barnase was in turn discovered to form a cyclic domain-swapped "flower-like" trimeric adduct (Figure 6C) (315). Furthermore, barnase interaction with its inhibitor barstar has been recently discovered to induce the lysis of staphylococcal bacteria (112). We underline again that barnase was derivatized, either as a monomer or as a dimer, also with immuno-peptides to form Immuno-RNase derivatives that were cytotoxic against breast and ovarian cancers (87-89). Binase, instead, is a variant known to display a remarkable toxicity toward many tumor cells $(83,91)$, and is also accompanied with a relevant antiviral activity (92, 93, 331). Binase has been subsequently found to exist as a natural dimer $(90,332)$, and the presence of the swapping of the N-terminal domain has been strongly suggested. However, two alternative structural models did not confirm the actual presence of 3D-DS: in fact, two structures showing electrostatic interactions have been proposed as being able to stabilize the interface between the two monomeric subunits of the native binase dimer (Figures 6D,E) (90). Interestingly, the variant balifase has also been characterized, apparently displaying a lower cytotoxicity than binase (84). Hence, further investigations on the structural determinants governing the important antitumor activity of these microbial RNases certainly deserve be performed to design future efficacious anticancer, as well as antimicrobial but possibly not immunogenic, RNase derivatives.

\section{CONCLUSIONS AND FUTURE PERSPECTIVES}

Several aspects of the catalytic, immunomodulatory and antitumor properties displayed by many RNases and by their oligomeric derivatives have been described in this review. Some results useful for therapy against still incurable cancers have been underlined or suggested as well. Although promising results have been already obtained with some RNases, and especially with ONC, improvements are necessary in terms of potentiating cytotoxicity and contemporarily attenuating or deleting undesired side-effects. To this end, RNases homo- or hetero-dimerization, or more extensive oligomerization, might certainly represent an efficacious strategy to be sharply tuned. 
The hetero-crosslinked immuno-RNases or the homo or hetero fusion-proteins have certainly offered promising results that could be hopefully transferred toward clinical use in the next future. However, the spontaneous or artificially induced non-covalent RNase self-association may also represent a fruitful pathway to produce active RNase derivatives.

Hence, the oligomerization tendency of, and the products formed by RNase A, BS-RNase, RNase 1 and ONC may suggest a smart future approach to build complex chimera products. From what has been reported, it emerges that the determinants driving a RNase to dimerize or oligomerize in a way that can make it cytotoxic depend on several features, comprising 3D-DS propensity, stability, basic nature of key-residues and geometry of the supramolecular adduct(s) formed. These features can affect crucial steps correlated with cytotoxicity, such as the interaction with the cell membrane, ability to enter the cytosol or to evade RI.

Therefore, and finally, the RNase oligomerization strategy should drive toward products accompanied with relevant antitumor activity but devoid of undesired side-effects. Moreover,

\section{REFERENCES}

1. D'Alessio G, Riordan JF. Ribonucleases: Structures and Functions. New York, NY: Academic Press (1997).

2. Barnard EA: Biological function of pancreatic ribonuclease. Nature. (1969) 221:340-4. doi: 10.1038/221340a0

3. Deutscher MP, Li Z. Exoribonucleases and their multiple roles in RNA metabolism. Prog Nucleic Acid Res Mol Biol. (2001) 66:67-105. doi: 10.1016/S0079-6603(00)66027-0

4. Beintema JJ, Schuller C, Irie M, Carsana A. Molecular evolution of the ribonuclease superfamily. Prog Biophys Mol Biol. (1988) 51:165-92. doi: 10.1016/0079-6107(88)90001-6

5. Sorrentino S, Libonati M. Human pancreatic-type and nonpancreatic-type ribonucleases: a direct side-by-side comparison of their catalytic properties. Arch Biochem Biophys. (1994) 312:340-8. doi: 10.1006/abbi.1994.1318

6. Beintema JJ, Kleineidam RG. The ribonuclease A superfamily: general discussion. Cell Mol Life Sci. (1998) 54:825-32. doi: 10.1007/s000180050211

7. Smyth DG, Stein WH, Moore S. The sequence of amino acid residues in bovine pancreatic ribonuclease: revisions and confirmations. J Biol Chem. (1963) 238:227-34.

8. Gutte B, Merrifield RB. The synthesis of ribonuclease A. J Biol Chem. (1971) 246:1922-41.

9. Moore S, Stein WH. Chemical structures of pancreatic ribonuclease and deoxyribonuclease. Science. (1973) 180:458-64. doi: $10.1126 /$ science. 180.4085 .458

10. Anfinsen CB. Principles that govern the folding of protein chains. Science. (1973) 181:223-30. doi: 10.1126/science.181.4096.223

11. Raines RT. Ribonuclease A. Chem Rev. (1998) 98:1045-66. doi: $10.1021 / \mathrm{cr} 960427 \mathrm{~h}$

12. Lomax JE, Eller CH, Raines RT. Comparative functional analysis of ribonuclease 1 homologs: molecular insights into evolving vertebrate physiology. Biochem J. (2017) 474:2219-33. doi: 10.1042/BCJ201 70173

13. Morita T, Niwata Y, Ohgi K, Ogawa M, Irie M. Distribution of two urinary ribonuclease-like enzymes in human organs and body fluids. J Biochem. (1986) 99:17-25. doi: 10.1093/oxfordjournals.jbchem.a135456

14. Beintema JJ, Wietzes P, Weickmann JL, Glitz DG. The amino acid sequence of human pancreatic ribonuclease. Anal Biochem. (1984) 136:4864. doi: 10.1016/0003-2697(84)90306-3

15. Ressler VT, Raines RT. Consequences of the endogenous Nglycosylation of human ribonuclease 1. Biochemistry. (2019) 58:987-96. doi: 10.1021/acs.biochem.8b01246 the RNase derivatives should be characterized by a satisfactory half-life in the circulatory system, to reach more easily the tumor place, thus allowing successful applications in therapy.

\section{AUTHOR CONTRIBUTIONS}

Both authors contributed to the manuscript: GG more about the structural and functional features of RNase oligomers, MM at higher extent about the biological aspects related to the activities of the RNase oligomers. GG built the figures and checked the overall english quality. MM critically helped to make the manuscript as much coherent and homogeneous as possible.

\section{FUNDING}

This work was funded by the Italian Ministry of University and Research (MIUR), through the Fondo Unico per la Ricerca FUR-GOTTE and FUR-MENEGAZZI.

16. Gotte G, Libonati M, Laurents DV. Glycosylation and specific deamidation of ribonuclease B affect the formation of three-dimensional domain-swapped oligomers. J Biol Chem. (2003) 278:46241-51. doi: 10.1074/jbc.M308470200

17. Suzuki H, Parente A, Farina B, Greco L, La Montagna R, Leone E. Complete amino-acid sequence of bovine seminal ribonuclease, a dimeric protein from seminal plasma. Biol Chem Hoppe Seyler. (1987) 368:1305-12. doi: 10.1515/bchm3.1987.368.2.1305

18. D’Alessio G, Parente A, Guida C, Leone E. Dimeric structure of seminal ribonuclease. FEBS Lett. (1972) 27:285-8. doi: 10.1016/0014-5793(72)80642-2

19. Mazzarella L, Capasso S, Demasi D, Di Lorenzo G, Mattia CA, Zagari A. Bovine seminal ribonuclease: structure at $1.9 \mathrm{~A}$ resolution. Acta Crystallogr D Biol Crystallogr. (1993) 49:389-402. doi: 10.1107/S09074449930 03403

20. Fett JW, Strydom DJ, Lobb RR, Alderman EM, Bethune JL, Riordan $\mathrm{JF}$, et al. Isolation and characterization of angiogenin, an angiogenic protein from human carcinoma cells. Biochemistry. (1985) 24:5480-6. doi: 10.1021/bi00341a030

21. Shapiro R, Riordan JF, Vallee BL. Characteristic ribonucleolytic activity of human angiogenin. Biochemistry. (1986) 25:3527-32. doi: 10.1021/bi00360a008

22. Shapiro R, Fett JW, Strydom DJ, Vallee BL. Isolation and characterization of a human colon carcinoma-secreted enzyme with pancreatic ribonuclease-like activity. Biochemistry. (1986) 25:7255-64. doi: 10.1021/bi00371a002

23. Saxena SK, Rybak SM, Davey RT Jr, Youle RJ, Ackerman EJ. Angiogenin is a cytotoxic, tRNA-specific ribonuclease in the RNase A superfamily. J Biol Chem. (1992) 267:21982-6.

24. Cho S, Beintema JJ, Zhang J. The ribonuclease A superfamily of mammals and birds: identifying new members and tracing evolutionary histories. Genomics. (2005) 85:208-20. doi: 10.1016/j.ygeno.2004.10.008

25. Arnold U. Stability and folding of amphibian ribonuclease A superfamily members in comparison with mammalian homologues. FEBS J. (2014) 281:3559-75. doi: 10.1111/febs.12891

26. Darzynkiewicz Z, Carter SP, Mikulski SM, Ardelt WJ, Shogen K. Cytostatic and cytotoxic effects of Pannon (P-30 Protein), a novel anticancer agent. Cell Tissue Kinet. (1988) 21:169-82. doi: 10.1111/j.1365-2184.1988.tb00855.x

27. Ardelt W, Shogen K, Darzynkiewicz Z. Onconase and amphinase, the antitumor ribonucleases from Rana pipiens oocytes. Curr Pharm Biotechnol. (2008) 9:215-25. doi: 10.2174/138920108784567245

28. Ardelt W, Mikulski SM, Shogen K. Amino acid sequence of an antitumor protein from Rana pipiens oocytes and early embryos. Homology to pancreatic ribonucleases. J Biol Chem. (1991) 266:245-51. 
29. McPherson A, Brayer G, Cascio D, Williams R. The mechanism of binding of a polynucleotide chain to pancreatic ribonuclease. Science. (1986) 232:765-8. doi: 10.1126/science.3961503

30. Nogues MV, Vilanova M, Cuchillo CM. Bovine pancreatic ribonuclease A as a model of an enzyme with multiple substrate binding sites. Biochim Biophys Acta. (1995) 1253:16-24. doi: 10.1016/0167-4838(95)00138-K

31. Prats-Ejarque G, Blanco JA, Salazar VA, Nogues VM, Moussaoui M, Boix E. Characterization of an RNase with two catalytic centers. Human RNase6 catalytic and phosphate-binding site arrangement favors the endonuclease cleavage of polymeric substrates. Biochim Biophys Acta Gen Subj. (2019) 1863:105-17. doi: 10.1016/j.bbagen.2018.09.021

32. Fischer S, Nishio M, Dadkhahi S, Gansler J, Saffarzadeh M, Shibamiyama A, et al. Expression and localisation of vascular ribonucleases in endothelial cells. Thromb Haemost. (2011) 105:345-55. doi: 10.1160/TH10-06-0345

33. Sorrentino S, Glitz DG, Hamann KJ, Loegering DA, Checkel JL, Gleich GJ. Eosinophil-derived neurotoxin and human liver ribonuclease. Identity of structure and linkage of neurotoxicity to nuclease activity. J Biol Chem. (1992) 267:14859-65

34. Beintema JJ, Hofsteenge J, Iwama M, Morita $\mathrm{T}$, Ohgi $\mathrm{K}$, Irie $\mathrm{M}$, et al. Amino acid sequence of the nonsecretory ribonuclease of human urine. Biochemistry. (1988) 27:4530-8. doi: 10.1021/bi00412a046

35. Rosenberg HF. Eosinophil-derived neurotoxin (EDN/RNase 2) and the mouse eosinophil-associated RNases (mEars): expanding roles in promoting host defense. Int J Mol Sci. (2015) 16:15442-55. doi: 10.3390/ijms160715442

36. Boix E, Nogues MV. Mammalian antimicrobial proteins and peptides: overview on the RNase A superfamily members involved in innate host defence. Mol Biosyst. (2007) 3:317-35. doi: 10.1039/b617527a

37. Qiu Z, Dyer KD, Xie Z, Radinger M, Rosenberg HF. GATA transcription factors regulate the expression of the human eosinophil-derived neurotoxin (RNase 2) gene. J Biol Chem. (2009) 284:13099-109. doi: 10.1074/jbc.M807307200

38. Shamri R, Young KM, Weller PF. PI3K, ERK, p38 MAPK and integrins regulate CCR3-mediated secretion of mouse and human eosinophilassociated RNases. Allergy. (2013) 68:880-9. doi: 10.1111/all.12163

39. $\mathrm{Lu} \mathrm{L}$, Li J, Moussaoui M, Boix E. Immune modulation by human secreted RNases at the extracellular space. Front Immunol. (2018) 9:1012. doi: 10.3389/fimmu.2018.01012

40. Barker RL, Loegering DA, Ten RM, Hamann KJ, Pease LR, Gleich GJ. Eosinophil cationic protein cDNA. Comparison with other toxic cationic proteins and ribonucleases. J Immunol. (1989) 143:952-5.

41. Boix E, Leonidas DD, Nikolovski Z, Nogues MV, Cuchillo CM, Acharya KR. Crystal structure of eosinophil cationic protein at $2.4 \mathrm{~A}$ resolution. Biochemistry. (1999) 38:16794-801. doi: 10.1021/bi9919145

42. Boix E, Torrent M, Sanchez D, Nogues MV. The antipathogen activities of eosinophil cationic protein. Curr Pharm Biotechnol. (2008) 9:141-52. doi: 10.2174/138920108784567353

43. Rosenberg HF. Recombinant human eosinophil cationic protein. Ribonuclease activity is not essential for cytotoxicity. J Biol Chem. (1995) 270:7876-81. doi: 10.1074/jbc.270.14.7876

44. Schwartz L, Cohen A, Thomas J, Spencer JD. The Immunomodulatory and antimicrobial properties of the vertebrate ribonuclease A superfamily. Vaccines (Basel). (2018) 6:76. doi: 10.3390/vaccines6040076

45. Venge P, Bystrom J, Carlson M, Hakansson L, Karawacjzyk M, Peterson C, et al. Eosinophil cationic protein (ECP): molecular and biological properties and the use of ECP as a marker of eosinophil activation in disease. Clin Exp Allergy. (1999) 29:1172-86. doi: 10.1046/j.1365-2222.1999.00542.x

46. Torrent M, Odorizzi F, Nogues MV, Boix E. Eosinophil cationic protein aggregation: identification of an $\mathrm{N}$-terminus amyloid prone region. Biomacromolecules. (2010) 11:1983-90. doi: 10.1021/bm100334u

47. Zhou HM, Strydom DJ. The amino acid sequence of human ribonuclease 4, a highly conserved ribonuclease that cleaves specifically on the $3^{\prime}$ side of uridine. Eur J Biochem. (1993) 217:401-10. doi: 10.1111/j.1432-1033.1993.tb18259.x

48. Liang S, Acharya KR. Structural basis of substrate specificity in porcine RNase 4. FEBS J. (2016) 283:912-28. doi: 10.1111/febs.13646

49. Strydom DJ. The angiogenins. Cell Mol Life Sci. (1998) 54:811-24. doi: $10.1007 / \mathrm{s} 000180050210$
50. Li S, Sheng J, Hu JK, Yu W, Kishikawa H, Hu MG, et al. Ribonuclease 4 protects neuron degeneration by promoting angiogenesis, neurogenesis, and neuronal survival under stress. Angiogenesis. (2013) 16:387-404. doi: 10.1007/s10456-012-9322-9

51. Padhi AK, Gomes J. A molecular dynamics based investigation reveals the role of rare Ribonuclease 4 variants in amyotrophic lateral sclerosis susceptibility. Mutat Res. (2019) 813:1-12. doi: 10.1016/j.mrfmmm.2018.11.002

52. Padhi AK, Narain P, Dave U, Satija R, Patir A, Gomes J. Insights into the role of ribonuclease 4 polymorphisms in amyotrophic lateral sclerosis. J Biomol Struct Dyn. (2019) 37:116-30. doi: 10.1080/07391102.2017.1419147

53. Rosenberg HF. RNase A ribonucleases and host defense: an evolving story. $J$ Leukoc Biol. (2008) 83:1079-87. doi: 10.1189/jlb.1107725

54. Sheng J, Xu Z. Three decades of research on angiogenin: a review and perspective. Acta Biochim Biophys Sin (Shanghai). (2016) 48:399-410. doi: 10.1093/abbs/gmv131

55. Hoang TT, Raines RT. Molecular basis for the autonomous promotion of cell proliferation by angiogenin. Nucleic Acids Res. (2017) 45:818-31. doi: 10.1093/nar/gkw1192

56. Tsuji T, Sun Y, Kishimoto K, Olson KA, Liu S, Hirukawa S, et al. Angiogenin is translocated to the nucleus of HeLa cells and is involved in ribosomal RNA transcription and cell proliferation. Cancer Res. (2005) 65:1352-60. doi: 10.1158/0008-5472.CAN-04-2058

57. Padhi AK, Jayaram B, Gomes J. Prediction of functional loss of human angiogenin mutants associated with ALS by molecular dynamics simulations. Sci Rep. (2013) 3:1225. doi: 10.1038/srep01225

58. Bradshaw WJ, Rehman S, Pham TT, Thiyagarajan N, Lee RL, Subramanian $\mathrm{V}$, et al. Structural insights into human angiogenin variants implicated in Parkinson's disease and Amyotrophic Lateral Sclerosis. Sci Rep. (2017) 7:41996. doi: 10.1038/srep41996

59. van Es MA, Schelhaas HJ, van Vught PW, Ticozzi N, Andersen PM, Groen EJ, et al. Angiogenin variants in Parkinson disease and amyotrophic lateral sclerosis. Ann Neurol. (2011) 70:964-73. doi: 10.1002/ana.22611

60. Saikia M, Hatzoglou M. The many virtues of tRNA-derived stressinduced RNAs (tiRNAs): discovering novel mechanisms of stress response and effect on human health. J Biol Chem. (2015) 290:29761-8. doi: 10.1074/jbc.R115.694661

61. Lyons SM, Fay MM, Akiyama Y, Anderson PJ, Ivanov P. RNA biology of angiogenin: current state and perspectives. RNA Biol. (2017) 14:171-8. doi: 10.1080/15476286.2016.1272746

62. Thomas SP, Hoang TT, Ressler VT, Raines RT. Human angiogenin is a potent cytotoxin in the absence of ribonuclease inhibitor. RNA. (2018) 24:1018-27. doi: 10.1261/rna.065516.117

63. Pizzo E, Sarcinelli C, Sheng J, Fusco S, Formiggini F, Netti P, et al. Ribonuclease/angiogenin inhibitor 1 regulates stress-induced subcellular localization of angiogenin to control growth and survival. J Cell Sci. (2013) 126:4308-19. doi: 10.1242/jcs.134551

64. Prats-Ejarque G, Arranz-Trullen J, Blanco JA, Pulido D, Nogues MV, Moussaoui M, et al. The first crystal structure of human RNase 6 reveals a novel substrate-binding and cleavage site arrangement. Biochem J. (2016) 473:1523-36. doi: 10.1042/BCJ20160245

65. Becknell B, Eichler TE, Beceiro S, Li B, Easterling RS, Carpenter AR, et al. Ribonucleases 6 and 7 have antimicrobial function in the human and murine urinary tract. Kidney Int. (2015) 87:151-61. doi: 10.1038/ ki.2014.268

66. Pulido D, Arranz-Trullen J, Prats-Ejarque G, Velazquez D, Torrent $\mathrm{M}$, Moussaoui $\mathrm{M}$, et al. Insights into the antimicrobial mechanism of action of human RNase6: structural determinants for bacterial cell agglutination and membrane permeation. Int J Mol Sci. (2016) 17:552. doi: 10.3390/ijms17040552

67. Lu L, Arranz-Trullen J, Prats-Ejarque G, Pulido D, Bhakta S, Boix E. Human antimicrobial RNases inhibit intracellular bacterial growth and induce autophagy in mycobacteria-infected macrophages. Front Immunol. (2019) 10:1500. doi: 10.3389/fimmu.2019.01500

68. Harder J, Schroder JM. RNase 7, a novel innate immune defense antimicrobial protein of healthy human skin. J Biol Chem. (2002) 277:4677984. doi: 10.1074/jbc.M207587200 
69. Zhang J, Dyer KD, Rosenberg HF. RNase 8, a novel RNase A superfamily ribonuclease expressed uniquely in placenta. Nucleic Acids Res. (2002) 30:1169-75. doi: 10.1093/nar/30.5.1169

70. Koczera P, Martin L, Marx G, Schuerholz T. The ribonuclease A superfamily in humans: canonical RNases as the buttress of innate immunity. Int J Mol Sci. (2016) 17:E1278. doi: 10.3390/ijms17081278

71. Sorrentino S. The eight human "canonical" ribonucleases: molecular diversity, catalytic properties, and special biological actions of the enzyme proteins. FEBS Lett. (2010) 584:2194-200. doi: 10.1016/j.febslet.2010.04.018

72. Shapiro R, Vallee BL. Site-directed mutagenesis of histidine-13 and histidine114 of human angiogenin. Alanine derivatives inhibit angiogenin-induced angiogenesis. Biochemistry. (1989) 28:7401-8. doi: 10.1021/bi00444a038

73. Kim JS, Soucek J, Matousek J, Raines RT. Catalytic activity of bovine seminal ribonuclease is essential for its immunosuppressive and other biological activities. Biochem J. (1995) 308:547-50. doi: 10.1042/bj3080547

74. Leland PA, Staniszewski KE, Park C, Kelemen BR, Raines RT. The ribonucleolytic activity of angiogenin. Biochemistry. (2002) 41:1343-50. doi: 10.1021/bi0117899

75. Dostal J, Matousek J. Isolation and some chemical properties of aspermatogenic substance from bull seminal vesicle fluid. J Reprod Fertil. (1973) 33:263-74. doi: 10.1530/jrf.0.0330263

76. Soucek J, Chudomel V, Potmesilova I, Novak JT. Effect of ribonucleases on cell-mediated lympholysis reaction and on GM-CFC colonies in bone marrow culture. Nat Immun Cell Growth Regul. (1986) 5:250-8.

77. Tamburrini M, Scala G, Verde C, Ruocco MR, Parente A, Venuta S, et al. Immunosuppressive activity of bovine seminal RNase on T-cell proliferation. Eur J Biochem. (1990) 190:145-8. doi: 10.1111/j.1432-1033.1990.tb15557.x

78. Matousek J. Ribonucleases and their antitumor activity. Comp Biochem Physiol C Toxicol Pharmacol. (2001) 129:175-91. doi: 10.1016/S1532-0456(01)90202-9

79. Yoshida H. The ribonuclease T1 family. Methods Enzymol. (2001) 341:28-41. doi: 10.1016/S0076-6879(01)41143-8

80. Hartley RW. Barnase and Barstar: two small proteins to fold and fit together. Trends Biochem Sci. (1989) 14:450-4. doi: 10.1016/0968-0004(89)90104-7

81. Hartley RW. Barnase-Barstar interaction. Methods Enzymol. (2001) 341:599611. doi: 10.1016/S0076-6879(01)41179-7

82. Ulyanova V, Vershinina V, Ilinskaya O. Barnase and binase: twins with distinct fates. FEBS J. (2011) 278:3633-43. doi: 10.1111/j.1742-4658.2011.08294.x

83. Makarov AA, Kolchinsky A, Ilinskaya ON. Binase and other microbial RNases as potential anticancer agents. Bioessays. (2008) 30:781-90. doi: 10.1002/bies.20789

84. Sokurenko Y, Nadyrova A, Ulyanova V, Ilinskaya O. Extracellular ribonuclease from Bacillus licheniformis (Balifase), a new member of the N1/T1 RNase superfamily. Biomed Res Int. (2016) 2016:4239375. doi: $10.1155 / 2016 / 4239375$

85. Dudkina E, Ulyanova V, Shah Mahmud R, Khodzhaeva V, Dao L, Vershinina $\mathrm{V}$, et al. Three-step procedure for preparation of pure Bacillus altitudinis ribonuclease. FEBS Open Bio. (2016) 6:24-32. doi: 10.1002/2211-5463.12023

86. Timofeev VP, Balandin TG, Tkachev YV, Novikov VV, Lapuk VA, Deev SM. Dynamic spin label study of the Barstar-Barnase complex. Biochemistry (Mosc). (2007) 72:994-1002. doi: 10.1134/S0006297907090118

87. Edelweiss E, Balandin TG, Ivanova JL, Lutsenko GV, Leonova OG, Popenko $\mathrm{VI}$, et al. Barnase as a new therapeutic agent triggering apoptosis in human cancer cells. PLoS ONE. (2008) 3:e2434. doi: 10.1371/journal.pone.0002434

88. Balandin TG, Edelweiss E, Andronova NV, Treshalina EM, Sapozhnikov AM, Deyev SM. Antitumor activity and toxicity of anti-HER2 immunoRNase scFv 4D5-dibarnase in mice bearing human breast cancer xenografts. Invest New Drugs. (2011) 29:22-32. doi: 10.1007/s10637-009-9329-2

89. Ivanova JL, Edelweiss EF, Leonova OG, Balandin TG, Popenko VI, Deyev SM. Immunocytochemical Visualization of P185HER2 receptor using antibodies fused with dibarnase and conjugate of Barstar with colloidal gold. Mol Biol (Mosk). (2013) 47:11. doi: 10.1134/S0026893313050063

90. Dudkina E, Kayumov A, Ulyanova V, Ilinskaya O. New insight into secreted ribonuclease structure: binase is a natural dimer. PLOS ONE. (2014) 9:e115818. doi: 10.1371/journal.pone.0115818

91. Ilinskaya ON, Zelenikhin PV, Petrushanko IY, Mitkevich VA, Prassolov VS, Makarov AA. Binase induces apoptosis of transformed myeloid cells and does not induce T-cell immune response. Biochem Biophys Res Commun. (2007) 361:1000-5. doi: 10.1016/j.bbrc.2007.07.143

92. Mitkevich VA, Burnysheva KM, Petrushanko IY, Adzhubei AA, Schulga AA, Chumakov PM, et al. Binase treatment increases interferon sensitivity and apoptosis in SiHa cervical carcinoma cells by downregulating E6 and E7 human papilloma virus oncoproteins. Oncotarget. (2017) 8:72666-75. doi: 10.18632/oncotarget.20199

93. Muller C, Ulyanova V, Ilinskaya O, Pleschka S, Mahmud RS. A novel antiviral strategy against MERS-CoV and $\mathrm{HCoV}-229 \mathrm{E}$ using binase to target viral genome replication. BioNanoScience. (2017) 7:6. doi: 10.1007/s12668-016-0341-7

94. Ilinskaya ON, Singh I, Dudkina E, Ulyanova V, Kayumov A, Barreto G. Direct inhibition of oncogenic KRAS by Bacillus pumilus ribonuclease (binase). Biochim Biophys Acta. (2016) 1863:1559-67. doi: 10.1016/j.bbamcr.2016.04.005

95. Luhtala N, Parker R. T2 Family ribonucleases: ancient enzymes with diverse roles. Trends Biochem Sci. (2010) 35:253-9. doi: 10.1016/j.tibs.2010.02.002

96. Baranzini N, Pedrini E, Girardello R, Tettamanti G, de Eguileor M, Taramelli $\mathrm{R}$, et al. Human recombinant RNASET2-induced inflammatory response and connective tissue remodeling in the medicinal leech. Cell Tissue Res. (2017) 368:337-51. doi: 10.1007/s00441-016-2557-9

97. Henneke M, Diekmann S, Ohlenbusch A, Kaiser J, Engelbrecht V, Kohlschutter A, et al. RNASET2-deficient cystic leukoencephalopathy resembles congenital cytomegalovirus brain infection. Nat Genet. (2009) 41:773-5. doi: 10.1038/ng.398

98. Benito A, Ribo M, Vilanova M. On the track of antitumour ribonucleases. Mol Biosyst. (2005) 1:294-302. doi: 10.1039/b502847g

99. Mitkevich VA, Ilinskaya ON, Makarov AA. Antitumor RNases: killer's secrets. Cell Cycle. (2015) 14:931-2. doi: 10.1080/15384101.2015.1 010972

100. Kannemeier C, Shibamiya A, Nakazawa F, Trusheim H, Ruppert C, Markart P, et al. Extracellular RNA constitutes a natural procoagulant cofactor in blood coagulation. Proc Natl Acad Sci USA. (2007) 104:6388-93. doi: 10.1073/pnas.0608647104

101. Fischer S, Gerriets T, Wessels C, Walberer M, Kostin S, Stolz E, et al. Extracellular RNA mediates endothelial-cell permeability via vascular endothelial growth factor. Blood. (2007) 110:2457-65. doi: 10.1182/blood-2006-08-040691

102. Cabrera-Fuentes HA, Ruiz-Meana M, Simsekyilmaz S, Kostin S, Inserte J, Saffarzadeh $\mathrm{M}$, et al. RNase1 prevents the damaging interplay between extracellular RNA and tumour necrosis factor-alpha in cardiac ischaemia/reperfusion injury. Thromb Haemost. (2014) 112:1110-9. doi: 10.1160/th14-08-0703

103. Kluever AK, Deindl E. Extracellular RNA, a potential drug target for alleviating atherosclerosis, ischemia/reperfusion injury and organ transplantation. Curr Pharm Biotechnol. (2018) 19:1189-95. doi: 10.2174/1389201020666190102150610

104. Dhondt B, Rousseau Q, De Wever O, Hendrix A. Function of extracellular vesicle-associated miRNAs in metastasis. Cell Tissue Res. (2016) 365:621-41. doi: $10.1007 / \mathrm{s} 00441-016-2430-\mathrm{x}$

105. Sadik N, Cruz L, Gurtner A, Rodosthenous RS, Dusoswa SA, Ziegler O, et al. Extracellular RNAs: a new awareness of old perspectives. Methods Mol Biol. (2018) 1740:1-15. doi: 10.1007/978-1-4939-7652-2_1

106. Vickers KC, Palmisano BT, Shoucri BM, Shamburek RD, Remaley AT. MicroRNAs are transported in plasma and delivered to recipient cells by high-density lipoproteins. Nat Cell Biol. (2011) 13:423-33. doi: $10.1038 /$ ncb 2210

107. Fischer S, Gesierich S, Griemert B, Schanzer A, Acker T, Augustin HG, et al. Extracellular RNA liberates tumor necrosis factor-alpha to promote tumor cell trafficking and progression. Cancer Res. (2013) 73:5080-9. doi: 10.1158/0008-5472.CAN-12-4657

108. Rybak SM, Newton DL. Natural and engineered cytotoxic ribonucleases: therapeutic potential. Exp Cell Res. (1999) 253:325-35. doi: 10.1006/excr.1999.4718

109. Potenza N, Salvatore V, Migliozzi A, Martone V, Nobile V, Russo A. Hybridase activity of human ribonuclease-1 revealed by a realtime fluorometric assay. Nucleic Acids Res. (2006) 34:2906-13. doi: $10.1093 / \mathrm{nar} / \mathrm{gkl} 368$ 
110. Libonati M, Sorrentino S. Degradation of double-stranded RNA by mammalian pancreatic-type ribonucleases. Methods Enzymol. (2001) 341:234-48. doi: 10.1016/S0076-6879(01)41155-4

111. Gaur D, Seth D, Batra JK. Glycine 38 is crucial for the ribonucleolytic activity of human pancreatic ribonuclease on doublestranded RNA. Biochem Biophys Res Commun. (2002) 297:390-5. doi: 10.1016/S0006-291X(02)02216-7

112. Hjelm LC, Nilvebrant J, Nygren PA, Nilsson AS, Seijsing J. Lysis of staphylococcal cells by modular lysin domains linked via a noncovalent Barnase-Barstar interaction bridge. Front Microbiol. (2019) 10:558. doi: 10.3389/fmicb.2019.00558

113. Lee HH, Wang YN, Hung MC. Functional roles of the human ribonuclease A superfamily in RNA metabolism and membrane receptor biology. Mol Aspects Med. (2019). doi: 10.1016/j.mam.2019.03.003

114. Kobe B, Deisenhofer J. Crystal structure of porcine ribonuclease inhibitor, a protein with leucine-rich repeats. Nature. (1993) 366:751-6. doi: $10.1038 / 366751 \mathrm{a} 0$

115. Libonati M, Gotte G. Oligomerization of bovine ribonuclease A: structural and functional features of its multimers. Biochem J. (2004) 380:311-27. doi: 10.1042/bj20031922

116. Libonati M, Gotte G, Vottariello F. A novel biological actions acquired by ribonuclease through oligomerization. Curr Pharm Biotechnol. (2008) 9:200-9. doi: 10.2174/138920108784567308

117. Gotte G, Laurents DV, Merlino A, Picone D, Spadaccini R. Structural and functional relationships of natural and artificial dimeric bovine ribonucleases: new scaffolds for potential antitumor drugs. FEBS Lett. (2013) 587:3601-8. doi: 10.1016/j.febslet.2013.09.038

118. Leich F, Stohr N, Rietz A, Ulbrich-Hofmann R, Arnold U. Endocytotic internalization as a crucial factor for the cytotoxicity of ribonucleases. J Biol Chem. (2007) 282:27640-6. doi: 10.1074/jbc.M702240200

119. Wu Y, Mikulski SM, Ardelt W, Rybak SM, Youle RJ. A cytotoxic ribonuclease. Study of the mechanism of onconase cytotoxicity. J Biol Chem. (1993) 268:10686-93.

120. Haigis MC, Raines RT. Secretory ribonucleases are internalized by a dynamin-independent endocytic pathway. J Cell Sci. (2003) 116:313-24. doi: $10.1242 /$ jcs.00214

121. Sundlass NK, Eller CH, Cui Q, Raines RT. Contribution of electrostatics to the binding of pancreatic-type ribonucleases to membranes. Biochemistry. (2013) 52:6304-12. doi: 10.1021/bi400619m

122. Notomista E, Mancheno JM, Crescenzi O, Di Donato A, Gavilanes J, D'Alessio G. The role of electrostatic interactions in the antitumor activity of dimeric RNases. FEBS J. (2006) 273:3687-697. doi: 10.1111/j.1742-4658.2006.05373.x

123. Turcotte RF, Lavis LD, Raines RT. Onconase cytotoxicity relies on the distribution of its positive charge. FEBS J. (2009) 276:3846-57. doi: 10.1111/j.1742-4658.2009.07098.x

124. D’Errico G, Ercole C, Lista M, Pizzo E, Falanga A, Galdiero S, et al. Enforcing the positive charge of N-termini enhances membrane interaction and antitumor activity of bovine seminal ribonuclease. Biochim Biophys Acta. (2011) 1808:3007-15. doi: 10.1016/j.bbamem.2011.08.009

125. Fiorini C, Gotte G, Donnarumma F, Picone D, Donadelli M. Bovine seminal ribonuclease triggers Beclin1-mediated autophagic cell death in pancreatic cancer cells. Biochim Biophys Acta. (2014) 1843:976-84. doi: 10.1016/j.bbamcr.2014.01.025

126. Sundlass NK, Raines RT. Arginine residues are more effective than lysine residues in eliciting the cellular uptake of onconase. Biochemistry. (2011) 50:10293-9. doi: 10.1021/bi200979k

127. Johnson RJ, Chao TY, Lavis LD, Raines RT. Cytotoxic ribonucleases: the dichotomy of Coulombic forces. Biochemistry. (2007) 46:10308-16. doi: $10.1021 /$ bi700857u

128. Mastronicola MR, Piccoli R, D’Alessio G. Key extracellular and intracellular steps in the antitumor action of seminal ribonuclease. Eur J Biochem. (1995) 230:242-9. doi: 10.1111/j.1432-1033.1995.tb20557.x

129. Arnold U. Aspects of the cytotoxic action of ribonucleases. Curr Pharm Biotechnol. (2008) 9:161-8. doi: 10.2174/138920108784567263

130. Rodriguez M, Torrent G, Bosch M, Rayne F, Dubremetz JF, Ribo M, et al. Intracellular pathway of onconase that enables its delivery to the cytosol. $J$ Cell Sci. (2007) 120:1405-11. doi: 10.1242/jcs.03427
131. Bracale A, Spalletti-Cernia D, Mastronicola M, Castaldi F, Mannucci R, Nitsch L, et al. Essential stations in the intracellular pathway of cytotoxic bovine seminal ribonuclease. Biochem J. (2002) 362:553-60. doi: 10.1042/bj3620553

132. Wu Y, Saxena SK, Ardelt W, Gadina M, Mikulski SM, De Lorenzo C, et al. A study of the intracellular routing of cytotoxic ribonucleases. J Biol Chem. (1995) 270:17476-81. doi: 10.1074/jbc.270.29.17476

133. Erickson HA, Jund MD, Pennell CA. Cytotoxicity of human RNase-based immunotoxins requires cytosolic access and resistance to ribonuclease inhibition. Protein Eng Des Sel. (2006) 19:37-45. doi: 10.1093/protein/gzi073

134. De Lorenzo C, Arciello A, Cozzolino R, Palmer DB, Laccetti P, Piccoli R, et al. A fully human antitumor immunoRNase selective for ErbB-2-positive carcinomas. Cancer Res. (2004) 64:4870-4. doi: 10.1158/0008-5472.CAN-03-3717

135. Liu X, Zhang P, He D, Rodl W, Preiss T, Radler JO, et al. pHreversible cationic RNase a conjugates for enhanced cellular delivery and tumor cell killing. Biomacromolecules. (2016) 17:173-82. doi: 10.1021/acs.biomac.5b01289

136. Benito A, Vilanova M, Ribo M. Intracellular routing of cytotoxic pancreatic-type ribonucleases. Curr Pharm Biotechnol. (2008) 9:169-79. doi: $10.2174 / 138920108784567281$

137. Thiyagarajan N, Ferguson R, Subramanian V, Acharya KR. Structural and molecular insights into the mechanism of action of human angiogenin-ALS variants in neurons. Nat Commun. (2012) 3:1121. doi: 10.1038/ncomms2126

138. Moroianu J, Riordan JF. Identification of the nucleolar targeting signal of human angiogenin. Biochem Biophys Res Commun. (1994) 203:1765-72. doi: 10.1006/bbrc. 1994.2391

139. Raines RT, Toscano MP, Nierengarten DM, Ha JH, Auerbach R. Replacing a surface loop endows ribonuclease A with angiogenic activity. J Biol Chem. (1995) 270:17180-4. doi: 10.1074/jbc.270.29.17180

140. Bosch M, Benito A, Ribo M, Puig T, Beaumelle B, Vilanova M. A nuclear localization sequence endows human pancreatic ribonuclease with cytotoxic activity. Biochemistry. (2004) 43:2167-77. doi: 10.1021/bi035729+

141. Vert A, Castro J, Ruiz-Martinez S, Tubert P, Escribano D, Ribo M, et al. Generation of new cytotoxic human ribonuclease variants directed to the nucleus. Mol Pharm. (2012) 9:2894-902. doi: 10.1021/mp300217b

142. Blackburn P. Ribonuclease inhibitor from human placenta: rapid purification and assay. J Biol Chem. (1979) 254:12484-7.

143. Lee FS, Shapiro R, Vallee BL. Tight-binding inhibition of angiogenin and ribonuclease A by placental ribonuclease inhibitor. Biochemistry. (1989) 28:225-30. doi: 10.1021/bi00427a031

144. Furia A, Moscato M, Cali G, Pizzo E, Confalone E, Amoroso MR, et al. The ribonuclease/angiogenin inhibitor is also present in mitochondria and nuclei. FEBS Lett. (2011) 585:613-7. doi: 10.1016/j.febslet.2011.01.034

145. Monti DM, Montesano Gesualdi N, Matousek J, Esposito F, D’Alessio G. The cytosolic ribonuclease inhibitor contributes to intracellular redox homeostasis. FEBS Lett. (2007) 581:930-4. doi: 10.1016/j.febslet.2007.01.072

146. Kobe B, Deisenhofer J. A structural basis of the interactions between leucine-rich repeats and protein ligands. Nature. (1995) 374:183-6. doi: 10.1038/374183a0

147. Johnson RJ, McCoy JG, Bingman CA, Phillips GN Jr, Raines RT. Inhibition of human pancreatic ribonuclease by the human ribonuclease inhibitor protein. J Mol Biol. (2007) 368:434-49. doi: 10.1016/j.jmb.2007.02.005

148. Papageorgiou AC, Shapiro R, Acharya KR. Molecular recognition of human angiogenin by placental ribonuclease inhibitor-an X-ray crystallographic study at $2.0 \mathrm{~A}$ resolution. EMBO J. (1997) 16:5162-77. doi: 10.1093/emboj/16.17.5162

149. Iyer S, Holloway DE, Kumar K, Shapiro R, Acharya KR. Molecular recognition of human eosinophil-derived neurotoxin (RNase 2) by placental ribonuclease inhibitor. J Mol Biol. (2005) 347:637-55. doi: 10.1016/j.jmb.2005.01.035

150. Spencer JD, Schwaderer AL, Eichler T, Wang H, Kline J, Justice SS, et al. An endogenous ribonuclease inhibitor regulates the antimicrobial activity of ribonuclease 7 in the human urinary tract. Kidney Int. (2014) 85:1179-91. doi: 10.1038/ki.2013.395

151. Lomax JE, Bianchetti CM, Chang A, Phillips GN Jr, Fox BG, Raines RT. Functional evolution of ribonuclease inhibitor: insights from birds and reptiles. J Mol Biol. (2014) 426:3041-56. doi: 10.1016/j.jmb.2014.06.007 
152. Rutkoski TJ, Raines RT. Evasion of ribonuclease inhibitor as a determinant of ribonuclease cytotoxicity. Curr Pharm Biotechnol. (2008) 9:185-9. doi: 10.2174/138920108784567344

153. Kobe B, Deisenhofer J. Mechanism of ribonuclease inhibition by ribonuclease inhibitor protein based on the crystal structure of its complex with ribonuclease A. J Mol Biol. (1996) 264:1028-43. doi: 10.1006/jmbi.1996.0694

154. Turcotte RF, Raines RT. Interaction of onconase with the human ribonuclease inhibitor protein. Biochem Biophys Res Commun. (2008) 377:512-4. doi: 10.1016/j.bbrc.2008.10.032

155. Dickson KA, Dahlberg CL, Raines RT. Compensating effects on the cytotoxicity of ribonuclease A variants. Arch Biochem Biophys. (2003) 415:172-7. doi: 10.1016/S0003-9861(03)00214-5

156. Rutkoski TJ, Kurten EL, Mitchell JC, Raines RT. Disruption of shapecomplementarity markers to create cytotoxic variants of ribonuclease A. $J$ Mol Biol. (2005) 354:41-54. doi: 10.1016/j.jmb.2005.08.007

157. Fuchs SM, Rutkoski TJ, Kung VM, Groeschl RT, Raines RT. Increasing the potency of a cytotoxin with an arginine graft. Protein Eng Des Sel. (2007) 20:505-9. doi: 10.1093/protein/gzm051

158. Ledoux L. Action of ribonuclease on certain ascites tumours. Nature. (1955) 175:258-9. doi: 10.1038/175258b0

159. Ledoux L. Action of ribonuclease on two solid tumours in vivo. Nature. (1955) 176:36-7. doi: 10.1038/176036a0

160. Ledoux L. Action of ribonuclease on neoplastic growth. II. Action on Landschutz ascites cells in vitro. Biochim Biophys Acta. (1956) 20:369-77. doi: 10.1016/0006-3002(56)90298-0

161. Haigis MC, Kurten EL, Raines RT. Ribonuclease inhibitor as an intracellular sentry. Nucleic Acids Res. (2003) 31:1024-32. doi: 10.1093/nar/gkg163

162. Antignani A, Naddeo M, Cubellis MV, Russo A, D'Alessio G. Antitumor action of seminal ribonuclease, its dimeric structure, and its resistance to the cytosolic ribonuclease inhibitor. Biochemistry. (2001) 40:3492-6. doi: 10.1021/bi002781m

163. Murthy BS, Sirdeshmukh R. Sensitivity of monomeric and dimeric forms of bovine seminal ribonuclease to human placental ribonuclease inhibitor. Biochem J. (1992) 281:343-8. doi: 10.1042/bj2810343

164. Kim JS, Soucek J, Matousek J, Raines RT. Mechanism of ribonuclease cytotoxicity. J Biol Chem. (1995) 270:31097-102. doi: 10.1074/jbc.270.52.31097

165. Dickson KA, Raines RT. Silencing an inhibitor unleashes a cytotoxic enzyme. Biochemistry. (2009) 48:5051-3. doi: 10.1021/bi900489y

166. Monti DM, D'Alessio G. Cytosolic RNase inhibitor only affects RNases with intrinsic cytotoxicity. J Biol Chem. (2004) 279:39195-8. doi: 10.1074/jbc.C400311200

167. Naddeo M, Vitagliano L, Russo A, Gotte G, D’Alessio G, Sorrentino S. Interactions of the cytotoxic RNase A dimers with the cytosolic ribonuclease inhibitor. FEBS Lett. (2005) 579:2663-8. doi: 10.1016/j.febslet.2005.03.087

168. Matousek J, Gotte G, Pouckova P, Soucek J, Slavik T, Vottariello F, et al. Antitumor activity and other biological actions of oligomers of ribonuclease A. J Biol Chem. (2003) 278:23817-22. doi: 10.1074/jbc.M302711200

169. Marianayagam NJ, Sunde M, Matthews JM. The power of two: protein dimerization in biology. Trends Biochem Sci. (2004) 29:618-25. doi: 10.1016/j.tibs.2004.09.006

170. Kumari N, Yadav S. Modulation of protein oligomerization: an overview. Prog Biophys Mol Biol. (2019). doi: 10.1016/j.pbiomolbio.2019.03.003

171. Wang D, Wilson G, Moore S. Preparation of cross-linked dimers of pancreatic ribonuclease. Biochemistry. (1976) 15:660-5. doi: 10.1021/bi00648a033

172. Rutkoski TJ, Kink JA, Strong LE, Schilling CI, Raines RT. Antitumor activity of ribonuclease multimers created by site-specific covalent tethering. Bioconjug Chem. (2010) 21:1691-702. doi: 10.1021/bc100292x

173. Ciglic MI, Jackson PJ, Raillard SA, Haugg M, Jermann TM, Opitz JG, et al. Origin of dimeric structure in the ribonuclease superfamily. Biochemistry. (1998) 37:4008-22. doi: 10.1021/bi972203e

174. Lin SH, Konishi Y, Denton ME, Scheraga HA. Influence of an extrinsic cross-link on the folding pathway of ribonuclease A. Conformational and thermodynamic analysis of cross-linked (lysine7-lysine41)ribonuclease a. Biochemistry. (1984) 23:5504-12. doi: 10.1021/bi003 $18 \mathrm{a} 019$
175. De Lorenzo C, D'Alessio G. Human anti-ErbB2 immunoagentsimmunoRNases and compact antibodies. FEBS J. (2009) 276:1527-35. doi: 10.1111/j.1742-4658.2009.06896.x

176. Riccio G, Borriello M, D’Alessio G, De Lorenzo C. A novel human antitumor dimeric immunoRNase. J Immunother. (2008) 31:440-5. doi: 10.1097/CJI.0b013e31816bc769

177. Kiesgen S, Arndt MAE, Korber C, Arnold U, Weber T, Halama N, et al. An EGF receptor targeting Ranpirnase-diabody fusion protein mediates potent antitumour activity in vitro and in vivo. Cancer Lett. (2015) 357:364-73. doi: 10.1016/j.canlet.2014.11.054

178. Hartman FC, Wold F. Cross-linking of bovine pancreatic ribonuclease A with dimethyl adipimidate. Biochemistry. (1967) 6:2439-48. doi: 10.1021/bi00860a021

179. Wang D, Moore S. Polyspermine-ribonuclease prepared by crosslinkage with dimethyl suberimidate. Biochemistry. (1977) 16:2937-42. doi: 10.1021/bi00632a021

180. Pouckova P, Morbio M, Vottariello F, Laurents DV, Matousek J, Soucek J, et al. Cytotoxicity of polyspermine-ribonuclease A and polyspermine-dimeric ribonuclease A. Bioconjug Chem. (2007) 18:1946-55. doi: $10.1021 / \mathrm{bc} 700253 \mathrm{c}$

181. Futami J, Yamada H. Design of cytotoxic ribonucleases by cationization to enhance intracellular protein delivery. Curr Pharm Biotechnol. (2008) 9:180-4. doi: 10.2174/138920108784567326

182. Green NS, Reisler E, Houk KN. Quantitative evaluation of the lengths of homobifunctional protein cross-linking reagents used as molecular rulers. Protein Sci. (2001) 10:1293-304. doi: 10.1110/ps.51201

183. Gotte G, Testolin L, Costanzo C, Sorrentino S, Armato U, Libonati M. Cross-linked trimers of bovine ribonuclease A: activity on doublestranded RNA and antitumor action. FEBS Lett. (1997) 415:308-12. doi: 10.1016/S0014-5793(97)01147-2

184. Bartholeyns J, Moore S. Pancreatic ribonuclease: enzymic and physiological properties of a cross-linked dimer. Science. (1974) 186:444-5. doi: $10.1126 /$ science.186.4162.444

185. Tarnowski GS, Kassel RL, Mountain IM, Blackburn P, Wilson G, Wang D. Comparison of antitumor activities of pancreatic ribonuclease and its cross-linked dimer. Cancer Res. (1976) 36:4074-8.

186. Rutkoski TJ, Kink JA, Strong LE, Raines RT. Human ribonuclease with a pendant poly(ethylene glycol) inhibits tumor growth in mice. Transl Oncol. (2013) 6:392-7. doi: 10.1593/tlo.13253

187. Pouckova P, Skvor J, Gotte G, Vottariello F, Slavik JT, Matousek J, et al. Some biological actions of PEG-conjugated RNase A oligomers. Neoplasma. (2006) 53:79-85

188. Vasandani VM, Burris JA, Sung C. Reversible nephrotoxicity of onconase and effect of lysine $\mathrm{pH}$ on renal onconase uptake. Cancer Chemother Pharmacol. (1999) 44:164-9. doi: 10.1007/s002800050962

189. Lopez-Alonso JP, Diez-Garcia F, Font J, Ribo M, Vilanova M, Scholtz JM, et al. Carbodiimide EDC induces cross-links that stabilize RNase A C-dimer against dissociation: EDC adducts can affect protein net charge, conformation, and activity. Bioconjug Chem. (2009) 20:1459-73. doi: $10.1021 /$ bc 9001486

190. Simons BL, Kaplan H, Fournier SM, Cyr T, Hefford MA. A novel crosslinked RNase A dimer with enhanced enzymatic properties. Proteins. (2007) 66:183-95. doi: 10.1002/prot.21144

191. Vottariello F, Costanzo C, Gotte G, Libonati M. “Zero-length” dimers of ribonuclease A: further characterization and no evidence of cytotoxicity. Bioconjug Chem. (2010) 21:635-45. doi: 10.1021/bc900407v

192. Futami J, Maeda T, Kitazoe M, Nukui E, Tada H, Seno M, et al. Preparation of potent cytotoxic ribonucleases by cationization: enhanced cellular uptake and decreased interaction with ribonuclease inhibitor by chemical modification of carboxyl groups. Biochemistry. (2001) 40:7518-24 doi: $10.1021 /$ bi010248g

193. Pouckova P, Zadinova M, Hlouskova D, Strohalm J, Plocova D, Spunda $\mathrm{M}$, et al. Polymer-conjugated bovine pancreatic and seminal ribonucleases inhibit growth of human tumors in nude mice. J Control Release. (2004) 95:83-92. doi: 10.1016/j.jconrel.2003.11.008

194. Matousek J, Tomanek M, Vottariello F, Morbio M, Gotte G, Libonati M. Degenerative action on mice and rat testes of polyspermine and its complexes with RNase A. J Appl Biomed. (2007) 5:26. doi: 10.32725/jab.2007.026 
195. Picone D, Donnarumma F, Ferraro G, Russo Krauss I, Fagagnini A, Gotte G, et al. Platinated oligomers of bovine pancreatic ribonuclease: structure and stability. J Inorg Biochem. (2015) 146:37-43. doi: 10.1016/j.jinorgbio.2015.02.011

196. Picone D, Donnarumma F, Ferraro G, Gotte G, Fagagnini A, Butera $\mathrm{G}$, et al. A comparison study on RNase A oligomerization induced by cisplatin, carboplatin and oxaliplatin. J Inorg Biochem. (2017) 173:105-12. doi: 10.1016/j.jinorgbio.2017.05.005

197. Nenci A, Gotte G, Bertoldi M, Libonati M. Structural properties of trimers and tetramers of ribonuclease A. Protein Sci. (2001) 10:2017-27. doi: 10.1110/ps.14101

198. Gotte G, Laurents DV, Libonati M. Three-dimensional domainswapped oligomers of ribonuclease A: identification of a fifth tetramer, pentamers and hexamers, and detection of trace heptameric, octameric and nonameric species. Biochim Biophys Acta. (2006) 1764:44-54. doi: 10.1016/j.bbapap.2005.10.011

199. Gotte G, Mahmoud Helmy A, Ercole C, Spadaccini R, Laurents DV, Donadelli $\mathrm{M}$, et al. Double domain swapping in bovine seminal RNase: formation of distinct $\mathrm{N}$ - and C-swapped tetramers and multimers with increasing biological activities. PLoS ONE. (2012) 7:e46804. doi: 10.1371/journal.pone.0046804

200. Fagagnini A, Pica A, Fasoli S, Montioli R, Donadelli M, Cordani M, Butturini E, Acquasaliente L, Picone D, Gotte G: Onconase dimerization through 3D domain swapping: structural investigations and increase in the apoptotic effect in cancer cells. Biochem J. (2017) 474:3767-81. doi: 10.1042/BCJ20170541

201. Fracasso G, Bellisola G, Castelletti D, Tridente G, Colombatti M. Immunotoxins and other conjugates: preparation and general characteristics. Mini Rev Med Chem. (2004) 4:545-62. doi: 10.2174/1389557043403909

202. Ayers NA, Nadeau OW, Read MW, Ray P, Carlson GM. Effectorsensitive cross-linking of phosphorylase $b$ kinase by the novel crosslinker 4-phenyl-1,2,4-triazoline-3,5-dione. Biochem J. (1998) 331:137-41. doi: 10.1042/bj3310137

203. Liu D, Cardillo TM, Wang Y, Rossi EA, Goldenberg DM, Chang CH. Trop-2-targeting tetrakis-ranpirnase has potent antitumor activity against triple-negative breast cancer. Mol Cancer. (2014) 13:53. doi: 10.1186/1476-4598-13-53

204. Wang X, Guo Z. Chlorotoxin-conjugated onconase as a potential anti-glioma drug. Oncol Lett. (2015) 9:1337-42. doi: 10.3892/ol.2014.2835

205. Newton DL, Hansen HJ, Mikulski SM, Goldenberg DM, Rybak SM. Potent and specific antitumor effects of an anti-CD22-targeted cytotoxic ribonuclease: potential for the treatment of non-Hodgkin lymphoma. Blood. (2001) 97:528-35. doi: 10.1182/blood.V97.2.528

206. Newton DL, Ilercil O, Laske DW, Oldfield E, Rybak SM, Youle RJ. Cytotoxic ribonuclease chimeras. Targeted tumoricidal activity in vitro and in vivo. $J$ Biol Chem. (1992) 267:19572-8.

207. Jinno H, Ueda M, Ozawa S, Kikuchi K, Ikeda T, Enomoto K, et al. Epidermal growth factor receptor-dependent cytotoxic effect by an EGFribonuclease conjugate on human cancer cell lines-a trial for less immunogenic chimeric toxin. Cancer Chemother Pharmacol. (1996) 38:3038. doi: 10.1007/s002800050487

208. Jinno H, Ueda M, Ozawa S, Ikeda T, Enomoto K, Psarras K, et al. Epidermal growth factor receptor-dependent cytotoxicity for human squamous carcinoma cell lines of a conjugate composed of human EGF and RNase 1. Life Sci. (1996) 58:1901-8. doi: 10.1016/0024-3205(96)00174-9

209. Leich F, Koditz J, Ulbrich-Hofman R, Arnold U. Tandemization endows bovine pancreatic ribonuclease with cytotoxic activity. J Mol Biol. (2006) 358:1305-13. doi: 10.1016/j.jmb.2006.03.007

210. De Lorenzo C, Nigro A, Piccoli R, D’Alessio G. A new RNase-based immunoconjugate selectively cytotoxic for ErbB2-overexpressing cells. FEBS Lett. (2002) 516:208-12. doi: 10.1016/S0014-5793(02)02527-9

211. Borriello M, Laccetti P, Terrazzano G, D’Alessio G, De Lorenzo C. A novel fully human antitumour immunoRNase targeting ErbB2-positive tumours. Br J Cancer. (2011) 104:1716-23. doi: 10.1038/bjc.2011.146

212. D'Avino C, Palmieri D, Braddom A, Zanesi N, James C, Cole S, et al. A novel fully human anti-NCL immunoRNase for triple-negative breast cancer therapy. Oncotarget. (2016) 7:87016-30. doi: 10.18632/oncotarget.13522
213. Futami J, Seno M, Ueda M, Tada H, Yamada H. Inhibition of cell growth by a fused protein of human ribonuclease 1 and human basic fibroblast growth factor. Protein Eng. (1999) 12:1013-9. doi: 10.1093/protein/12.11.1013

214. Psarras K, Ueda M, Tanabe M, Kitajima M, Aiso S, Komatsu S, et al. Targeting activated lymphocytes with an entirely human immunotoxin analogue: human pancreatic RNase1-human IL-2 fusion. Cytokine. (2000) 12:786-90. doi: $10.1006 /$ cyto.1999.0619

215. Menzel C, Schirrmann T, Konthur Z, Jostock T, Dubel S. Human antibody RNase fusion protein targeting CD30 ${ }^{+}$lymphomas. Blood. (2008) 111:38307. doi: 10.1182/blood-2007-04-082768

216. Krauss J, Arndt MA, Vu BK, Newton DL, Seeber S, Rybak SM. Efficient killing of CD22+ tumor cells by a humanized diabody-RNase fusion protein. Biochem Biophys Res Commun. (2005) 331:595-602. doi: 10.1016/j.bbrc.2005.03.215

217. Chang CH, Sapra P, Vanama SS, Hansen HJ, Horak ID, Goldenberg DM. Effective therapy of human lymphoma xenografts with a novel recombinant ribonuclease/anti-CD74 humanized IgG4 antibody immunotoxin. Blood. (2005) 106:4308-14. doi: 10.1182/blood-2005-03-1033

218. Zhao HL, Xue C, Du JL, Ren M, Xia S, Cheng YG, et al. Sustained and cancer cell targeted cytosolic delivery of Onconase results in potent antitumor effects. J Control Release. (2012) 159:346-52. doi: 10.1016/j.jconrel.2012.02.019

219. Kiesgen S, Liebers N, Cremer M, Arnold U, Weber T, Keller A, et al. A fusogenic dengue virus-derived peptide enhances antitumor efficacy of an antibody-ribonuclease fusion protein targeting the EGF receptor. Protein Eng Des Sel. (2014) 27:331-7. doi: 10.1093/protein/gzu040

220. Sun M, Tang H, Gao Y, Dai X, Yuan Y, Zhang C, et al. Constitutive expression and anticancer potency of a novel immunotoxin onconase-DV3. Oncol Rep. (2016) 35:1987-94. doi: 10.3892/or.2016.4570

221. Qi J, Ye X, Li L, Bai H, Xu C. Improving the specific antitumor efficacy of ONC by fusion with N-terminal domain of transferrin. Biosci Biotechnol Biochem. (2018) 82:1153-8. doi: 10.1080/09168451.2018.1456318

222. Newton DL, Xue Y, Olson KA, Fett JW, Rybak SM. Angiogenin single-chain immunofusions: influence of peptide linkers and spacers between fusion protein domains. Biochemistry. (1996) 35:545-53. doi: 10.1021/bi951650w

223. Cremer C, Vierbuchen T, Hein L, Fischer R, Barth S, Nachreiner T. Angiogenin mutants as novel effector molecules for the generation of fusion proteins with increased cytotoxic potential. J Immunother. (2015) 38:85-95. doi: 10.1097/CJI.0000000000000053

224. Arndt MA, Krauss J, Vu BK, Newton DL, Rybak SM. A dimeric angiogenin immunofusion protein mediates selective toxicity toward CD22 ${ }^{+}$tumor cells. J Immunother. (2005) 28:245-51. doi: 10.1097/01.cji.0000161396.96582.10

225. Newton DL, Nicholls PJ, Rybak SM, Youle RJ. Expression and characterization of recombinant human eosinophil-derived neurotoxin and eosinophil-derived neurotoxin-anti-transferrin receptor sFv. J Biol Chem. (1994) 269:26739-45.

226. Deonarain MP, Epenetos AA. Design, characterization and anti-tumour cytotoxicity of a panel of recombinant, mammalian ribonuclease-based immunotoxins. Br J Cancer. (1998) 77:537-46. doi: 10.1038/bjc.1998.87

227. Tome-Amat J, Menendez-Mendez A, Garcia-Ortega L, Batt CA, Onaderra M, Martinez-del-Pozo A, et al. Production and characterization of scFvA33T1, an immunoRNase targeting colon cancer cells. FEBS J. (2012) 279:3022-32. doi: 10.1111/j.1742-4658.2012.08683.x

228. De Lorenzo C, D'Alessio G. From immunotoxins to immunoRNases. Curr Pharm Biotechnol. (2008) 9:210-4. doi: 10.2174/138920108784 567254

229. De Lorenzo C, Di Malta C, Cali G, Troise F, Nitsch L, D'Alessio G. Intracellular route and mechanism of action of ERB-hRNase, a human anti-ErbB2 anticancer immunoagent. FEBS Lett. (2007) 581:296-300. doi: 10.1016/j.febslet.2006.12.034

230. Newton DL, Pollock D, DiTullio P, Echelard Y, Harvey M, Wilburn B, et al. Antitransferrin receptor antibody-RNase fusion protein expressed in the mammary gland of transgenic mice. J Immunol Methods. (1999) 231:159-67. doi: 10.1016/S0022-1759(99)00154-4

231. Messmann RA, Vitetta ES, Headlee D, Senderowicz AM, Figg WD, Schindler $\mathrm{J}$, et al. A phase I study of combination therapy with immunotoxins IgGHD37-deglycosylated ricin A chain (dgA) and IgG-RFB4-dgA (Combotox) 
in patients with refractory $\mathrm{CD} 19(+), \mathrm{CD} 22(+) \mathrm{B}$ cell lymphoma. Clin Cancer Res. (2000) 6:1302-13.

232. Arnold U, Leich F, Neumann P, Lilie H, Ulbrich-Hofmann R. Crystal structure of RNase A tandem enzymes and their interaction with the cytosolic ribonuclease inhibitor. FEBS J. (2011) 278:331-40. doi: 10.1111/j.1742-4658.2010.07957.x

233. Liu Y, Hart PJ, Schlunegger MP, Eisenberg D. The crystal structure of a 3D domain-swapped dimer of RNase A at a 2.1-A resolution. Proc Natl Acad Sci USA. (1998) 95:3437-42. doi: 10.1073/pnas.95.7.3437

234. Liu Y, Gotte G, Libonati M, Eisenberg D. A domain-swapped RNase A dimer with implications for amyloid formation. Nat Struct Biol. (2001) 8:211-4. doi: $10.1038 / 84941$

235. Liu Y, Eisenberg D. 3D domain swapping: as domains continue to swap. Protein Sci. (2002) 11:1285-99. doi: 10.1110/ps.0201402

236. Liu Y, Gotte G, Libonati M, Eisenberg D. Structures of the two 3D domain-swapped RNase A trimers. Protein Sci. (2002) 11:371-80. doi: $10.1110 /$ ps.36602

237. Cozza G, Moro S, Gotte G. Elucidation of the ribonuclease a aggregation process mediated by 3D domain swapping: a computational approach reveals possible new multimeric structures. Biopolymers. (2008) 89:26-39. doi: 10.1002/bip.20833

238. Rybak SM, Arndt MA, Schirrmann T, Dubel S, Krauss J. Ribonucleases and immunoRNases as anticancer drugs. Curr Pharm Des. (2009) 15:2665-75. doi: 10.2174/138161209788923921

239. Jordaan S, Akinrinmade OA, Nachreiner T, Cremer C, Naran K, Chetty S, et al. Updates in the development of ImmunoRNases for the selective killing of tumor cells. Biomedicines. (2018) 6:28. doi: 10.3390/biomedicines6010028

240. Matthews JM, Sunde M. Dimers, oligomers, everywhere. Adv Exp Med Biol. (2012) 747:1-18. doi: 10.1007/978-1-4614-3229-6_1

241. Bennett MJ, Schlunegger MP, Eisenberg D. 3D domain swapping: a mechanism for oligomer assembly. Protein Sci. (1995) 4:2455-68. doi: $10.1002 /$ pro. 5560041202

242. Bennett MJ, Choe S, Eisenberg D. Domain swapping: entangling alliances between proteins. Proc Natl Acad Sci USA. (1994) 91:3127-31. doi: 10.1073/pnas.91.8.3127

243. Bennett MJ, Sawaya MR, Eisenberg D. Deposition diseases and 3D domain swapping. Structure. (2006) 14:811-24. doi: 10.1016/j.str.2006.03.011

244. Gronenborn AM. Protein acrobatics in pairs-dimerization via domain swapping. Curr Opin Struct Biol. (2009) 19:39-49. doi: 10.1016/j.sbi.2008.12.002

245. Yang S, Cho SS, Levy Y, Cheung MS, Levine H, Wolynes PG, et al. Domain swapping is a consequence of minimal frustration. Proc Natl Acad Sci USA. (2004) 101:13786-91. doi: 10.1073/pnas.0403724101

246. Rousseau F, Schymkowitz J, Itzhaki LS. Implications of 3D domain swapping for protein folding, misfolding and function. Adv Exp Med Biol. (2012) 747:137-52. doi: 10.1007/978-1-4614-3229-6_9

247. Mackinnon SS, Malevanets A, Wodak SJ. Intertwined associations in structures of homooligomeric proteins. Structure. (2013) 21:638-49. doi: 10.1016/j.str.2013.01.019

248. Hirota S. Oligomerization of cytochrome c, myoglobin, and related heme proteins by 3D domain swapping. J Inorg Biochem. (2019) 194:170-9. doi: 10.1016/j.jinorgbio.2019.03.002

249. Knaus KJ, Morillas M, Swietnicki W, Malone M, Surewicz WK, Yee VC. Crystal structure of the human prion protein reveals a mechanism for oligomerization. Nat Struct Biol. (2001) 8:770-4. doi: 10.1038/nsb0901-770

250. Janowski R, Kozak M, Jankowska E, Grzonka Z, Grubb A, Abrahamson $M$, et al. Human cystatin C, an amyloidogenic protein, dimerizes through three-dimensional domain swapping. Nat Struct Biol. (2001) 8:316-20. doi: $10.1038 / 86188$

251. Orlikowska M, Jankowska E, Kolodziejczyk R, Jaskolski M, Szymanska A. Hinge-loop mutation can be used to control 3D domain swapping and amyloidogenesis of human cystatin C. J Struct Biol. (2011) 173:406-13. doi: 10.1016/j.jsb.2010.11.009

252. Liu C, Sawaya MR, Eisenberg D. Beta(2)-microglobulin forms three-dimensional domain-swapped amyloid fibrils with disulfide linkages. Nat Struct Mol Biol. (2011) 18:49-55. doi: 10.1038/nsm b.1948
253. Goldschmidt L, Teng PK, Riek R, Eisenberg D. Identifying the amylome, proteins capable of forming amyloid-like fibrils. Proc Natl Acad Sci USA. (2010) 107:3487-92. doi: 10.1073/pnas.0915166107

254. Sambashivan S, Liu Y, Sawaya MR, Gingery M, Eisenberg D. Amyloidlike fibrils of ribonuclease A with three-dimensional domain-swapped and native-like structure. Nature. (2005) 437:266-9. doi: 10.1038/nature03916

255. Teng PK, Anderson NJ, Goldschmidt L, Sawaya MR, Sambashivan S, Eisenberg D. Ribonuclease A suggests how proteins self-chaperone against amyloid fiber formation. Protein Sci. (2012) 21:26-37. doi: 10.1002/pro.754

256. Crestfield AM, Stein WH, Moore S. On the aggregation of bovine pancreatic ribonuclease. Arch Biochem Biophys. (1962) Suppl 1:217-22.

257. Fruchter RG, Crestfield AM. Preparation and properties of two active forms of ribonuclease dimer. J Biol Chem. (1965) 240:3868-74.

258. Libonati M. Molecular aggregates of ribonucleases. Some enzymatic properties. Ital J Biochem. (1969) 18:407-17.

259. Richards FM, Vithayathil PJ. The preparation of subtilisn-modified ribonuclease and the separation of the peptide and protein components. $J$ Biol Chem. (1959) 234:1459-65.

260. Doscher MS. Preparation of ribonuclease $S$ and its component parts, Speptide and S-protein. Methods Enzymol. (1967) 11:9.

261. Marzotto A, Galzigna L. Molecular aggregation of bovine pancreatic ribonuclease induced by substrate. Arch Biochem Biophys. (1970) 137:373-8. doi: 10.1016/0003-9861(70)90451-0

262. Gotte G, Vottariello F, Libonati M. Thermal aggregation of ribonuclease A. A contribution to the understanding of the role of $3 \mathrm{D}$ domain swapping in protein aggregation. J Biol Chem. (2003) 278:10763-9. doi: 10.1074/jbc.M213146200

263. Gotte G, Bertoldi M, Libonati M. Structural versatility of bovine ribonuclease A. Distinct conformers of trimeric and tetrameric aggregates of the enzyme. Eur J Biochem. (1999) 265:680-7. doi: 10.1046/j.1432-1327.1999.0 0761.x

264. Lopez-Alonso JP, Bruix M, Font J, Ribo M, Vilanova M, Jimenez MA, et al. NMR spectroscopy reveals that RNase A is chiefly denatured in $40 \%$ acetic acid: implications for oligomer formation by $3 \mathrm{D}$ domain swapping. $J \mathrm{Am}$ Chem Soc. (2010) 132:1621-30. doi: 10.1021/ja9081638

265. Lopez-Alonso JP, Gotte G, Laurents DV. Kinetic analysis provides insight into the mechanism of ribonuclease A oligomer formation. Arch Biochem Biophys. (2009) 489:41-7. doi: 10.1016/j.abb.2009.07.013

266. Benito A, Laurents DV, Ribo M, Vilanova M. The structural determinants that lead to the formation of particular oligomeric structures in the pancreatic-type ribonuclease family. Curr Protein Pept Sci. (2008) 9:370-93. doi: $10.2174 / 138920308785132695$

267. Gotte G, Donadelli M, Laurents DV, Vottariello F, Morbio M, Libonati M. Increase of RNase a $\mathrm{N}$-terminus polarity or $\mathrm{C}$-terminus apolarity changes the two domains' propensity to swap and form the two dimeric conformers of the protein. Biochemistry. (2006) 45:10795-806. doi: 10.1021/bi060933t

268. Gotte G, Libonati M. Oligomerization of ribonuclease A under reducing conditions. Biochim Biophys Acta. (2008) 1784:638-50. doi: 10.1016/j.bbapap.2007.12.013

269. Fagagnini A, Montioli R, Caloiu A, Ribo M, Laurents DV, Gotte G. Extensive deamidation of RNase A inhibits its oligomerization through 3D domain swapping. Biochim Biophys Acta. (2017) 1865:76-87. doi: 10.1016/j.bbapap.2016.10.008

270. Miller KH, Karr JR, Marqusee S. A hinge region cis-proline in ribonuclease A acts as a conformational gatekeeper for C-terminal domain swapping. J Mol Biol. (2010) 400:567-78. doi: 10.1016/j.jmb.2010.05.017

271. Esposito L, Donnarumma F, Ruggiero A, Leone S, Vitagliano L, Picone D. Structure, stability and aggregation propensity of a ribonuclease A-onconase chimera. Int J Biol Macromol. (2019) 133:1125-33. doi: 10.1016/j.ijbiomac.2019.04.164

272. Geiger R, Gautschi M, Thor F, Hayer A, Helenius A. Folding, quality control, and secretion of pancreatic ribonuclease in live cells. J Biol Chem. (2011) 286:5813-22. doi: 10.1074/jbc.M110.171694

273. Vottariello F, Giacomelli E, Frasson R, Pozzi N, De Filippis V, Gotte G. RNase A oligomerization through $3 \mathrm{D}$ domain swapping is favoured by a residue located far from the swapping domains. Biochimie. (2011) 93:1846-57. doi: 10.1016/j.biochi.2011.07.005 
274. Merlino A, Picone D, Ercole C, Balsamo A, Sica F. Chain termini cross-talk in the swapping process of bovine pancreatic ribonuclease. Biochimie. (2012) 94:1108-18. doi: 10.1016/j.biochi.2012.01.010

275. Lopez-Alonso JP, Bruix M, Font J, Ribo M, Vilanova M, Rico M, et al. Formation, structure, and dissociation of the ribonuclease $\mathrm{S}$ threedimensional domain-swapped dimer. J Biol Chem. (2006) 281:9400-6. doi: 10.1074/jbc.M510491200

276. Wang YN, Lee HH, Chou CK, Yang WH, Wei Y, Chen CT, et al. Angiogenin/ribonuclease 5 is an EGFR ligand and a serum biomarker for erlotinib sensitivity in pancreatic cancer. Cancer Cell. (2018) 33:752-69 e758. doi: 10.1016/j.ccell.2018.02.012

277. D'Alessio G, Malorni MC, Parente A. Dissociation of bovine seminal ribonuclease into catalytically active monomers by selective reduction and alkylation of the intersubunit disulfide bridges. Biochemistry. (1975) 14:1116-22. doi: 10.1021/bi00677a004

278. Piccoli R, Tamburrini M, Piccialli G, Di Donato A, Parente A, D'Alessio G. The dual-mode quaternary structure of seminal RNase. Proc Natl Acad Sci USA. (1992) 89:1870-4. doi: 10.1073/pnas.89.5.1870

279. Berisio R, Sica F, De Lorenzo C, Di Fiore A, Piccoli R, Zagari A, et al. Crystal structure of the dimeric unswapped form of bovine seminal ribonuclease. FEBS Lett. (2003) 554:105-10. doi: 10.1016/S0014-5793(03)01114-1

280. Adinolfi S, Piccoli R, Sica F, Mazzarella L. BS-RNase tetramers: an example of domain-swapped oligomers. FEBS Lett. (1996) 398:326-32. doi: 10.1016/S0014-5793(96)01034-4

281. Merlino A, Ercole C, Picone D, Pizzo E, Mazzarella L, Sica F. The buried diversity of bovine seminal ribonuclease: shape and cytotoxicity of the swapped non-covalent form of the enzyme. J Mol Biol. (2008) 376:427-37. doi: 10.1016/j.jmb.2007.11.008

282. Giancola C, Del Vecchio P, De Lorenzo C, Barone R, Piccoli R, D’Alessio $\mathrm{G}$, et al. Thermodynamic stability of the two isoforms of bovine seminal ribonuclease. Biochemistry. (2000) 39:7964-72. doi: 10.1021/bi992953j

283. Russo A, Antignani A, Giancola C, D'Alessio G. Engineering the refolding pathway and the quaternary structure of seminal ribonuclease by newly introduced disulfide bridges. J Biol Chem. (2002) 277:48643-9. doi: 10.1074/jbc.M207141200

284. Bracale A, Castaldi F, Nitsch L, D’Alessio G. A role for the intersubunit disulfides of seminal RNase in the mechanism of its antitumor action. Eur J Biochem. (2003) 270:1980-7. doi: 10.1046/j.1432-1033.2003.03567.x

285. Mazzarella L, Vitagliano L, Zagari A. Swapping structural determinants of ribonucleases: an energetic analysis of the hinge peptide 16-22. Proc Natl Acad Sci USA. (1995) 92:3799-803. doi: 10.1073/pnas.92.9.3799

286. Ercole C, Avitabile F, Del Vecchio P, Crescenzi O, Tancredi T, Picone D. Role of the hinge peptide and the intersubunit interface in the swapping of N-termini in dimeric bovine seminal RNase. Eur J Biochem. (2003) 270:4729-35. doi: 10.1046/j.1432-1033.2003.03872.x

287. Ercole C, Spadaccini R, Alfano C, Tancredi T, Picone D. A new mutant of bovine seminal ribonuclease with a reversed swapping propensity. Biochemistry. (2007) 46:2227-32. doi: 10.1021/bi0613630

288. D'Alessio G, Leone E. The action of seminal enzymes on ribonucleic acid. Biochem J. (1963) 89:7.

289. Libonati M, Floridi A. Breakdown of double-stranded RNA by bull semen ribonuclease. Eur J Biochem. (1969) 8:81-7. doi: 10.1111/j.1432-1033.1969.tb00498.x

290. Libonati M, Malorni MC, Parente A, D'Alessio G. Degradation of doublestranded RNA by a monomeric derivative of ribonuclease BS-1. Biochim Biophys Acta. (1975) 402:83-7. doi: 10.1016/0005-2787(75)90372-X

291. Laccetti P, Portella G, Mastronicola MR, Russo A, Piccoli R, D’Alessio G, et al. In vivo and in vitro growth-inhibitory effect of bovine seminal ribonuclease on a system of rat thyroid epithelial transformed cells and tumors. Cancer Res. (1992) 52:4582-6.

292. Lee JE, Raines RT. Cytotoxicity of bovine seminal ribonuclease: monomer versus dimer. Biochemistry. (2005) 44:15760-7. doi: 10.1021/bi05 $1668 \mathrm{z}$

293. Laccetti P, Spalletti-Cernia D, Portella G, De Corato P, D’Alessio G, Vecchio G. Seminal ribonuclease inhibits tumor growth and reduces the metastatic potential of Lewis lung carcinoma. Cancer Res. (1994) 54:4253-6.

294. Spalletti-Cernia D, Sorrentino R, Di Gaetano S, Arciello A, Garbi C, Piccoli $\mathrm{R}$, et al. Antineoplastic ribonucleases selectively kill thyroid carcinoma cells via caspase-mediated induction of apoptosis. J Clin Endocrinol Metab. (2003) 88:2900-7. doi: 10.1210/jc.2002-020373

295. Sica F, Di Fiore A, Merlino A, Mazzarella L. Structure and stability of the noncovalent swapped dimer of bovine seminal ribonuclease: an enzyme tailored to evade ribonuclease protein inhibitor. J Biol Chem. (2004) 279:36753-60. doi: 10.1074/jbc.M405655200

296. Sica F, Di Fiore A, Zagari A, Mazzarella L. The unswapped chain of bovine seminal ribonuclease: Crystal structure of the free and liganded monomeric derivative. Proteins. (2003) 52:263-71. doi: 10.1002/prot.10407

297. Di Donato A, Ciardiello MA, de Nigris M, Piccoli R, Mazzarella L, D'Alessio G. Selective deamidation of ribonuclease A. Isolation and characterization of the resulting isoaspartyl and aspartyl derivatives. J Biol Chem. (1993) 268:4745-51.

298. Di Donato A, Galletti P, D’Alessio G. Selective deamidation and enzymatic methylation of seminal ribonuclease. Biochemistry. (1986) 25:8361-8. doi: 10.1021/bi00374a005

299. Di Donato A, Cafaro V, D’Alessio G. Ribonuclease A can be transformed into a dimeric ribonuclease with antitumor activity. J Biol Chem. (1994) 269:17394-6.

300. Cafaro V, Bracale A, Di Maro A, Sorrentino S, D’Alessio G, Di Donato A. New muteins of RNase A with enhanced antitumor action. FEBS Lett. (1998) 437:149-152. doi: 10.1016/S0014-5793(98)01221-6

301. Vatzaki EH, Allen SC, Leonidas DD, Trautwein-Fritz K, Stackhouse J, Benner $\mathrm{SA}$, et al. Crystal structure of a hybrid between ribonuclease A and bovine seminal ribonuclease-the basic surface, at $2.0 \mathrm{~A}$ resolution. Eur J Biochem. (1999) 260:176-82. doi: 10.1046/j.1432-1327.1999.00142.x

302. Sica F, Pica A, Merlino A, Russo Krauss I, Ercole C, Picone D. The multiple forms of bovine seminal ribonuclease: structure and stability of a C-terminal swapped dimer. FEBS Lett. (2013) 587:3755-62. doi: 10.1016/j.febslet.2013.10.003

303. Canals A, Pous J, Guasch A, Benito A, Ribo M, Vilanova M, et al. The structure of an engineered domain-swapped ribonuclease dimer and its implications for the evolution of proteins toward oligomerization. Structure. (2001) 9:967-76. doi: 10.1016/S0969-2126(01)00659-1

304. Russo N, Antignani A, D’Alessio G. In vitro evolution of a dimeric variant of human pancreatic ribonuclease. Biochemistry. (2000) 39:3585-91. doi: 10.1021/bi992367q

305. Leland PA, Staniszewski KE, Kim BM, Raines RT. Endowing human pancreatic ribonuclease with toxicity for cancer cells. J Biol Chem. (2001) 276:43095-102. doi: 10.1074/jbc.M106636200

306. Bal HP, Batra JK. Human pancreatic ribonuclease-deletion of the carboxyl-terminal EDST extension enhances ribonuclease activity and thermostability. Eur J Biochem. (1997) 245:465-9. doi: 10.1111/j.1432-1033.1997.t01-1-00465.x

307. Piccoli R, Di Gaetano S, De Lorenzo C, Grauso M, Monaco C, SpallettiCernia D, et al. A dimeric mutant of human pancreatic ribonuclease with selective cytotoxicity toward malignant cells. Proc Natl Acad Sci USA. (1999) 96:7768-73. doi: 10.1073/pnas.96.14.7768

308. Spalletti-Cernia D, Sorrentino R, Di Gaetano S, Piccoli R, Santoro M, D'Alessio G, et al. Highly selective toxic and proapoptotic effects of two dimeric ribonucleases on thyroid cancer cells compared to the effects of doxorubicin. Br J Cancer. (2004) 90:270-7. doi: 10.1038/sj.bjc.6601491

309. Merlino A, Avella G, Di Gaetano S, Arciello A, Piccoli R, Mazzarella L, et al. Structural features for the mechanism of antitumor action of a dimeric human pancreatic ribonuclease variant. Protein Sci. (2009) 18:50-7. doi: $10.1002 /$ pro.6

310. Attery A, Dey P, Tripathi P, Batra JK. A ribonuclease inhibitor resistant dimer of human pancreatic ribonuclease displays specific antitumor activity. Int J Biol Macromol. (2018) 107:1965-70. doi: 10.1016/j.ijbiomac.2017.10.067

311. Benito A, Bosch M, Torrent G, Ribo M, Vilanova M. Stabilization of human pancreatic ribonuclease through mutation at its $\mathrm{N}$-terminal edge. Protein Eng. (2002) 15:887-93. doi: 10.1093/protein/15.11.887

312. Merlino A, Vitagliano L, Ceruso MA, Mazzarella L. Dynamic properties of the N-terminal swapped dimer of ribonuclease A. Biophys J. (2004) 86:2383-91. doi: 10.1016/S0006-3495(04)74295-2

313. Pica A, Merlino A, Buell AK, Knowles TP, Pizzo E, D’Alessio G, et al. Three-dimensional domain swapping and supramolecular protein assembly: insights from the X-ray structure of a dimeric swapped variant of human 
pancreatic RNase. Acta Crystallogr D Biol Crystallogr. (2013) 69:2116-23. doi: 10.1107/S0907444913020507

314. Rodriguez M, Benito A, Ribo M, Vilanova M. Characterization of the dimerization process of a domain-swapped dimeric variant of human pancreatic ribonuclease. FEBS J. (2006) 273:1166-76. doi: 10.1111/j.1742-4658.2006.05141.x

315. Zegers I, Deswarte J, Wyns L. Trimeric domain-swapped barnase. Proc Natl Acad Sci USA. (1999) 96:818-22. doi: 10.1073/pnas.96.3.818

316. Lee JE, Bae E, Bingman CA, Phillips GN Jr, Raines RT. Structural basis for catalysis by onconase. J Mol Biol. (2008) 375:165-77. doi: 10.1016/j.jmb.2007.09.089

317. Vert A, Castro J, Ribo M, Benito A, Vilanova M. Activating transcription factor 3 is crucial for antitumor activity and to strengthen the antiviral properties of Onconase. Oncotarget. (2017) 8:11692-707. doi: 10.18632/oncotarget.14302

318. Titani K, Takio K, Kuwada M, Nitta K, Sakakibara F, Kawauchi $\mathrm{H}$, et al. Amino acid sequence of sialic acid binding lectin from frog (Rana catesbeiana) eggs. Biochemistry. (1987) 26:2189-94. doi: 10.1021/bi00382a018

319. Saxena SK, Gravell M, Wu YN, Mikulski SM, Shogen K, Ardelt W, et al. Inhibition of HIV-1 production and selective degradation of viral RNA by an amphibian ribonuclease. J Biol Chem. (1996) 271:20783-8. doi: $10.1074 / \mathrm{jbc} .271 .34 .20783$

320. Suhasini AN, Sirdeshmukh R. Onconase action on tRNA(Lys3), the primer for HIV-1 reverse transcription. Biochem Biophys Res Commun. (2007) 363:304-9. doi: 10.1016/j.bbrc.2007.08.157

321. Qiao M, Zu LD, He XH, Shen RL, Wang QC, Liu MF. Onconase downregulates microRNA expression through targeting microRNA precursors. Cell Res. (2012) 22:1199-202. doi: 10.1038/cr.2012.67

322. Ardelt W, Ardelt B, Darzynkiewicz Z. Ribonucleases as potential modalities in anticancer therapy. Eur J Pharmacol. (2009) 625:181-9. doi: 10.1016/j.ejphar.2009.06.067

323. Porta C, Paglino C, Mutti L. Ranpirnase and its potential for the treatment of unresectable malignant mesothelioma. Biologics. (2008) 2:6019. doi: 10.2147/BTT.S2383

324. Wang XM, Guo ZY. Recombinant expression, different downstream processing of the disulfide-rich anti-tumor peptide Ranpirnase and its effect on the growth of human glioma cell line SHG-44. Biomed Rep. (2013) 1:747-50. doi: 10.3892/br.2013.138

325. Fiorini C, Cordani M, Gotte G, Picone D, Donadelli M. Onconase induces autophagy sensitizing pancreatic cancer cells to gemcitabine and activates
Akt/mTOR pathway in a ROS-dependent manner. Biochim Biophys Acta. (2015) 1853:549-60. doi: 10.1016/j.bbamcr.2014.12.016

326. Raineri A, Prodomini S, Fasoli S, Gotte G, Menegazzi M. Influence of onconase in the therapeutic potential of PARP inhibitors in A375 malignant melanoma cells. Biochem Pharmacol. (2019) 167:173-81. doi: 10.1016/j.bcp.2019.06.006

327. Leland PA, Staniszewski KE, Kim B, Raines RT. A synapomorphic disulfide bond is critical for the conformational stability and cytotoxicity of an amphibian ribonuclease. FEBS Lett. (2000) 477:203-7. doi: 10.1016/S0014-5793(00)01804-4

328. Notomista E, Catanzano F, Graziano G, Di Gaetano S, Barone G, Di Donato A. Contribution of chain termini to the conformational stability and biological activity of onconase. Biochemistry. (2001) 40:9097-103. doi: $10.1021 / \mathrm{bi010741s}$

329. Chen DT, Lin A. Domain swapping in ribonuclease T1 allows the acquisition of double-stranded activity. Protein Eng. (2002) 15:997-1003. doi: 10.1093/protein/15.12.997

330. Yuki S, Kondo Y, Kato F, Kato M, Matsuo N. Noncytotoxic ribonuclease, RNase $\mathrm{T} 1$, induces tumor cell death via hemagglutinating virus of Japan envelope vector. Eur J Biochem. (2004) 271:3567-72. doi: 10.1111/j.0014-2956.2004.04293.x

331. Shah Mahmud R, Muller C, Romanova Y, Mostafa A, Ulyanova V, et al. Ribonuclease from bacillus acts as an antiviral agent against negative- and positive-sense single stranded human respiratory RNA viruses. Biomed Res Int. (2017) 2017:5279065. doi: 10.1155/2017/5 279065

332. Ermakova E. Brownian dynamics simulation of the competitive reactions: binase dimerization and the association of binase and barstar. Biophys Chem. (2007) 130:26-31. doi: 10.1016/j.bpc.200 7.06 .012

Conflict of Interest: The authors declare that the research was conducted in the absence of any commercial or financial relationships that could be construed as a potential conflict of interest.

Copyright (๑) 2019 Gotte and Menegazzi. This is an open-access article distributed under the terms of the Creative Commons Attribution License (CC BY). The use, distribution or reproduction in other forums is permitted, provided the original author(s) and the copyright owner(s) are credited and that the original publication in this journal is cited, in accordance with accepted academic practice. No use, distribution or reproduction is permitted which does not comply with these terms. 